\title{
Hindcasting the impacts of land-use changes on bird communities with species distribution models of Bird Atlas data
}

\author{
Adrián Regos,,${ }^{1,2,9}$ Louis Imbeau, ${ }^{3}$ Mélanie Desrochers, ${ }^{4}$ Alain Leduc, ${ }^{4}$ Michel Robert, ${ }^{5}$ Benoît Jobin, ${ }^{5}$ \\ Lluís Brotons, ${ }^{6,7,8}$ and Pierre Drapeau ${ }^{4}$ \\ ${ }^{1}$ Departamento de Zooloxía, Xenética e Antropoloxía Fisica, Universidade de Santiago de Compostela, Campus Sur, \\ Santiago de Compostela, Spain \\ ${ }^{2}$ Research Centre in Biodiversity and Genetic Resources (CIBIOIInBIO), ECOCHANGE Group, Campus Agrario de Vairão, Vairão, Portugal \\ ${ }^{3}$ Centre d'étude de la forêt, Institut de Recherche sur les Forêts (IRF), Université du Québec en Abitibi-Témiscamingue (UQAT), 445 \\ boulevard de l' Université, Rouyn-Noranda, Quebec J9X $5 E 4$ Canada \\ ${ }^{4}$ Département des sciences biologiques, Université du Québec à Montréal (UQAM), Centre d'étude de la forêt, 141 Avenue Président-Kennedy, \\ Montréal, Québec H2X 1 Y4 Canada \\ ${ }^{5}$ Service canadien de la faune, Environnement et changement climatique Canada, 801-1550, avenue d'Estimauville, \\ Québec, Québec G1J 0C3 Canada \\ ${ }^{6}$ Forest Sciences Centre of Catalonia (CEMFOR-CTFC), InForest Joint Research Unit (CSIC-CTFC-CREAF), Solsona, Spain \\ ${ }^{7}$ Centre de Recerca Ecològica i Aplicacions Forestals (CREAF), Cerdanyola del Vallés, Spain \\ ${ }^{8}$ Consejo Superior de Investigaciones Científicas (CSIC), Cerdanyola del Vallés, Spain
}

\begin{abstract}
Habitat loss and degradation induced by human development are among the major threats to biodiversity worldwide. In this study, we tested our ability to predict the response of bird communities (128 species) to land-use changes in southern Quebec $\left(\sim 483,100 \mathrm{~km}^{2}\right)$ over the last $30 \mathrm{yr}$ (between 1984-1989 and 2010-2014) by using species distribution models (299,302 occurrences in 30,408 locations) from a hindcasting perspective. Results were grouped by functional guilds to infer potential impacts on ecosystem services, and to relate model transferability (i.e., ability of our models to be generalized to other times and scales) to specific functional and life-history traits. Overall, our models were able to accurately predict, both in space and time, habitat suitability for $69 \%$ of species, especially for granivorous, nonmigrant, tree-nesting species, and species that are tied to agricultural areas under intensive use. These findings indicate that model transferability depends upon specific functional and life-history traits, providing further evidence that species' ecologies affect the ability of models to accurately predict bird distributions. Declining bird species were mostly short-distance migrants that were associated with open habitats (agricultural and nonproductive forest) with aerial insectivorous or granivorous diets, which may be related to agricultural intensification and land abandonment. Land-use changes were positive for some forest bird species that were mainly associated with mixed and deciduous forests, generalist diets and tree-nesting strategies. Yet cavity-nesting birds have suffered substantial reductions in their distributions, suggesting that cumulative effects of intensive logging and wildfires on mature forests pose a threat for forest-specialist species. Habitat suitability changes predicted by our coarse-scale species distribution models partially agreed with the long-term trends reported by the North American Breeding Bird Survey. Our findings confirm land-use change as a key driving force for shaping bird communities in southern Quebec, together with the need to explicitly incorporate it into global change scenarios that better inform decision-makers on conservation and management.
\end{abstract}

Key words: agricultural intensification; bird atlas; ecological traits; habitat suitability modeling; hindcasting; land abandonment; temporal transferability.

\section{INTRODUCTION}

Habitat loss and degradation that are brought about by land-use changes induced by human development are among the major threats to biodiversity worldwide (Millennium Ecosystem Assessment 2005, Newbold et al. 2015, WWF 2016). The manner in which biodiversity responds to these ongoing, large-scale changes is still unclear: this is a serious concern given its importance for maintaining ecosystem functioning and services (Isbell et al. 2011). The Aichi Biodiversity Target 7 for 2011-2020, which was set by the Convention on Biological Diversity (CBD), aims at

Manuscript received 10 November 2017; revised 25 May 2018; accepted 15 July 2018. Corresponding Editor: John M. Marzluff.

${ }^{9}$ E-mail: adrian.regos@usc.es sustainably managing areas under agriculture and forestry to ensure conservation of biodiversity (CBD 2010). To meet this challenge, it is necessary to evaluate how the industrial deployment of contemporary agricultural and forestry practices has changed the current state of biodiversity through concomitant habitat changes. This requires having access to long-term monitoring data on biodiversity that can be linked with past and current habitat data and for which accurate quantitative species-habitat models can be derived and compared through time. Such combinations of data sets are rarely at hand, but species-habitat statistical models for a given time period may be used to hindcast or forecast organism responses to habitat changes through time (Guisan and Zimmermann 2000, Strauss and Biedermann 2007). These models assume that contemporary species-habitat relationships are likely to remain quite stable, given that they 
are the product of evolutionary adaptation to historical variation in habitat conditions (Drapeau et al. 2016).

Despite a general recognition that land-use change is one of the main factor responsible for biodiversity decline (Millennium Ecosystem Assessment 2005, Secretariat of the Convention on Biological Diversity 2014, Maxwell et al. 2016), a recent analysis of the literature published over the last $25 \mathrm{yr}$ on biodiversity scenarios, paradoxically found that most of these studies are focused on the effect of climate change, ignoring the marked impact of land-use changes (Titeux et al. 2016a, b). Studies testing our ability to predict the response of biodiversity to land-use changes at large spatial and temporal scales are thus urgently needed for constructing plausible biodiversity scenarios, for which credibility is based upon sound quantitative relationships between communities and habitat alterations that are driven by land-use changes.

Across continents, birds are among the most intensively studied vertebrates for which we have sound knowledge regarding their ecology, distribution, and abundance (Gibson et al. 2011, Jenkins et al. 2013, Donaldson et al. 2016). Over the last 40 years, several volunteer programs aimed at refining bird abundance and distribution patterns led to the publication of national or regional Breeding Bird Atlases, which have considerably increased our understanding of the avifauna (Sharrock 1976, Yeatman 1976, Muntaner et al. 1983, Cadman et al. 1987, Gauthier and Aubry 1996, among others). In many regions, these programs have been conducted repeatedly to assess changes in bird abundance and distribution patterns (Gibbons et al. 1993, Estrada et al. 2004, Balmer et al. 2013). Thus, bird atlas data can be useful for modeling the contribution of land-use changes to species distribution patterns (but see Vallecillo et al. 2009). We hypothesize that the composition and structure of bird communities is strongly driven by land-use changes. We predict that observed changes in bird populations should be mainly associated with changes in species habitat availability.

In this paper, we use data from the first and second breeding bird atlases (Gauthier and Aubry 1996) to test our ability to predict the response of bird communities to land-use changes at large spatial and temporal scales (i.e., model transferability) by using a hindcasting perspective (i.e., backward prediction), to analyze how past land-cover/use changes have ultimately affected contemporary bird communities (data available online). ${ }^{10}$ More specifically, we asked the following questions: (1) What is the extent and direction of change in vegetation and land-use types (in terms of composition and structure) between the periods 1984-1989 and 2010-2014? (2) How well can we predict the response of bird species to landuse changes at large spatial and temporal scales? (3) How have bird communities been affected by these landuse changes? (4) How can specific functional and lifehistory traits influence model transferability, and bird species response to land-use changes?

\footnotetext{
${ }^{10} \mathrm{http}: / /$ www.atlas-oiseaux.qc.ca/index_en.jsp
}

\section{Methods}

\section{Study area}

The study region covers southern Quebec, which represents a large extent of eastern North America (Fig. 1), characterized by the transition of the deciduous southern temperate forest to boreal mixedwood and northern coniferous forest biomes (Fig. 1). This region has been subjected to human land-use changes involving two main impacts on landscapes: conversion (i.e., natural habitats altered by human use) and intensification (e.g., greater agricultural or forestry intensity). As is the case elsewhere around the world, arable soils have often shifted from 1980s onward to an industrialized agriculture that is mainly organized around massive conversion of traditional perennial crops (pasture and hayfields) to intensive annual crops (corn and soybean) resulting in a more homogeneous agricultural landscapes (Jobin et al. 2010). Conversely, the most southerly deciduous forest cover has increased as forest fragmentation decreased through agricultural abandonment and old farmlands (i.e., perennial crops) have transitioned to forests (Jobin et al. 2014). In boreal forest ecosystems, natural disturbances (e.g., fire and insect outbreaks), and industrial timber management operations (logging, road building) have also resulted in large-scale land-use implications (Kerr and Cihlar 2003, Imbeau et al. 2015). This is of special relevance given that contemporary disturbance rates (accumulating clear-cutting and fire) have increased compared to those observed during the preindustrial period (Drapeau et al. 2009a, Bouchard and Pothier 2011, Bergeron et al. 2017, Boucher et al. 2017). Hence, the cumulative effects of these two disturbance regimes might interact in a hardly predictable way with regard to future ecosystem resilience (Gauthier et al. 2015). While the human footprint of landuse changes has affected landscape patterns from the South to the North within the study area, its impacts on biodiversity, ecosystem functioning and services at large spatial and temporal scales remain less clear (but see Drapeau et al. 2000).

\section{Birds and functional traits}

Data on bird species were obtained from the two breeding bird survey campaigns that were conducted in Quebec (Canada) between 1984 and 1989 (Atlas 1; Gauthier and Aubry 1996) and between 2010 and 2014 (Atlas 2; see footnote 10), respectively. Both atlases are large-scale surveys of breeding birds roughly covering the southern forested biomes of Quebec $\left(\sim 483,100 \mathrm{~km}^{2}\right.$; Fig. 1). Atlas 1 was surveyed using a coarse-grained scale of $10-\mathrm{km}^{2}$ squares, whereas Atlas 2 comprised two approaches with two different scales: (1) a coarse-grained resolution (10-km square level) matching the same Universal Transverse Mercator (UTM) grid system as Atlas 1 and (2) a fine-grained resolution at the point-count level. At this fine-grained resolution, 30,408 point counts of 5 min duration with unlimited distance (Bibby et al. 1992) were undertaken during the breeding season, mainly between 25 May and 10 July of 2010 to 2014. Thereby, we obtained fine-grained bird data at roughly $1-\mathrm{km}$ resolution $(500 \mathrm{~m}$ radius around each point 


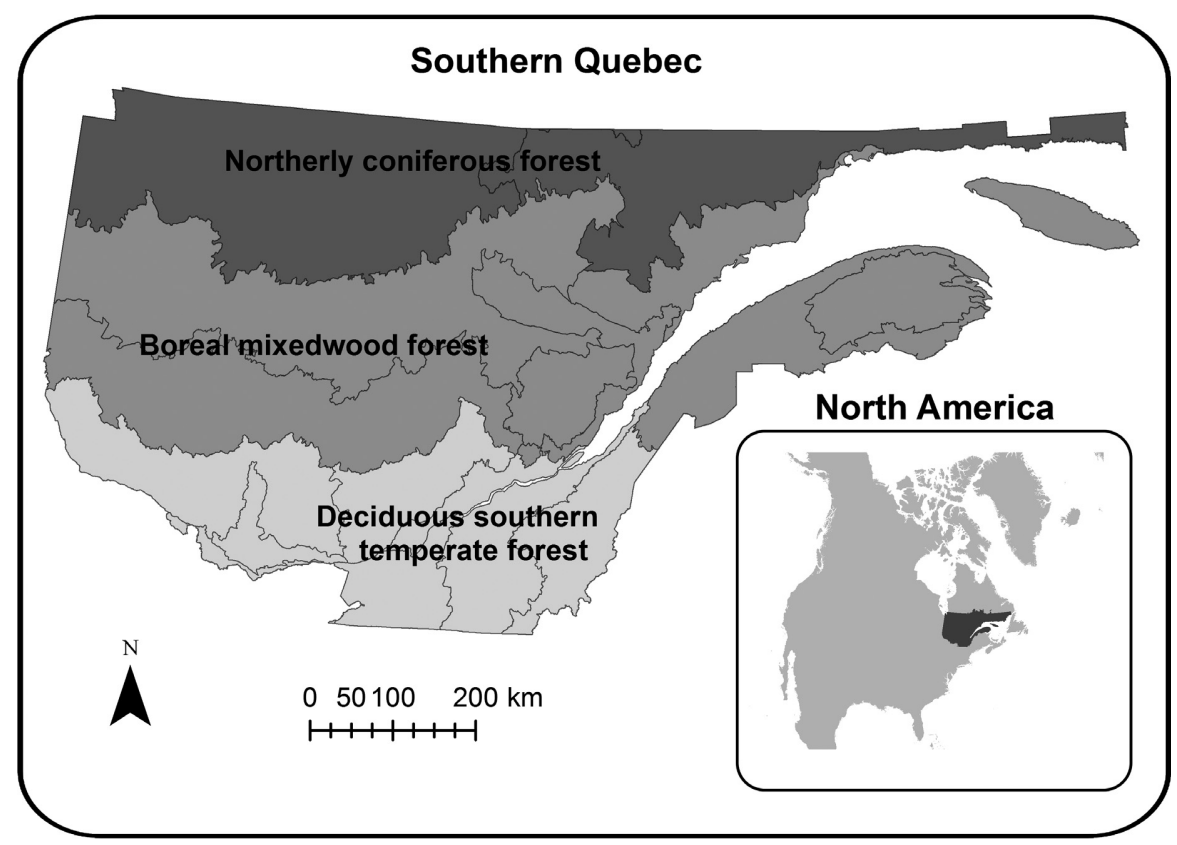

FIG. 1. Location of the study area (southern Quebec, Canada) in eastern North America, and its three dominant forest biomes: (1) the deciduous southern temperate forest; (2) boreal forest; and (3) northern coniferous forest. Reference system: NAD83/Quebec Lambert Projection (Lambert Conic Conformal).

count to account for the unlimited recording distance methodology and species' habitat perception) for the period 2010-2014 and coarse-grained bird distribution data at 10$\mathrm{km}$ resolution for 2010-2014 (Atlas 2) and 1984-1989 (Atlas 1) study periods.

Species with different ecological and functional traits are expected to respond differently to land-use changes since species responses within communities are nonrandom but rather linked with specific traits (Vandewalle et al. 2010, Diamond et al. 2011, Kimball et al. 2016). Ecologists have frequently analyzed bird community trends using groups of species that are potentially affected by land-use changes. In tropical forests, nonmigratory forest specialists with diets of fruit, nectar, or insects were found to be most sensitive to land-use intensity (Newbold et al. 2012, 2014). In temperate and boreal forests, migratory status or habitat associations such as forest-interior species (Freemark and Merriam 1986, McGarigal and McComb 1995) or mature and old forest species (Drapeau et al. 2000, 2016, Imbeau et al. 2001, Schmiegelow and Mönkkönen 2002) have been used to evaluate the sensitivity of birds to land management practices. We grouped bird species into four different functional guilds according to their habitat preferences, feeding, nesting, and migratory strategies (Appendix S1: Table S1). We estimated the habitat preference for each species as the ratio of the proportion of the habitat type within each point count where the species had been detected and the prevalence of the habitat type within southern Quebec, minus one (according to the methodology described in De Cáceres et al. 2013, see index values in Appendix S1: Table S2). This index allows us to group the species by different typologies of land-cover/use composition and vegetation structure. Feeding, nesting, and migratory strategies were assigned for each bird species according to data that were taken from Birds of North America (Rodewald 2015).

\section{Land-uselcover data}

We used the second and fourth decadal forest inventory conducted by the Quebec Ministry of Natural Resources (MRNQ) to reconstruct land-use/cover information for both periods, i.e., 1984-1989 and 2010-2014 (see Appendix S2: Fig. S1). Tree height, estimated age, and tree species composition were derived from photointerpretation of aerial photography, which was dated, respectively, from 1979-1990 and 2000-2015. Vector files of digital forest cover maps were then represented in grid format at a resolution of 14 ha (about 375-m resolution), in the Système d'Information Forestière par Tesselle (SIFORT; Pelletier et al. 2007). Agricultural information about use intensity (i.e., annual and perennial crops) was derived from a range of cloud-free Landsat TM and ETM + images that were obtained for 1993-1994 and 2014, respectively (see Jobin et al. 2003, 2010 for details) and the database of declared plots and agricultural production from the Insurance and Income Protection program (La Financière Agricole) of the Quebec government. We calculated the percentage of each landcover type (Table 1) at the two spatial scales: (1) a coarsegrained resolution $(10 \mathrm{~km}$ square level; values available for first and second atlas period in Data S1 and S2, respectively); and (2) a fine-grained resolution (within a radius of $500 \mathrm{~m}$ for each point count; values available in Data S3).

\section{Species distribution models and transferability}

To quantify changes in habitat suitability (i.e., the likelihood of species occurrence on the base of environmental 
variables) between 1984-1989 and 2010-2014, we constructed species distribution models (SDMs; Guisan and Zimmermann 2000, Brotons et al. 2008; see workflow in Fig. 2). A total of 299,302 species occurrences were gathered from the 30,408 point counts that were conducted between 2010 and 2014. From the initial data set of 221 species, we omitted those species with fewer than 30 presences for statistical reasons (i.e., to avoid risk of model overfitting; Wisz et al. 2008, Thuiller et al. 2014; see list of species in

TABLE 1. List, abbreviation, and brief description of each predictor variables used for fitting species distribution models (SDMs).

\begin{tabular}{ll}
\hline \hline Abbreviation & \multicolumn{1}{c}{ Description } \\
Wa & water \\
We & wetlands \\
Aa & annual agriculture (intensive use) \\
Ap & perennial agriculture (extensive use) \\
N-F & nonforestry (nonproductive forest) \\
Al & Alnus tree spp. \\
R & regeneration $(<4 \mathrm{~m}$ ) \\
D1 & young deciduous forest (tree height $<4 \mathrm{~m}$ ) \\
D2 & middle-age deciduous forest (tree height 4-12 m) \\
D3 & mature deciduous forest (tree height $\geq 12 \mathrm{~m}$ ) \\
M1 & young mixed forest (tree height $<4 \mathrm{~m})$ \\
M2 & middle-age mixed forest (tree height 4-12 m) \\
M3 & mature mixed forest (tree height $\geq 12 \mathrm{~m}$ ) \\
C1 & young coniferous forest (tree height $<4 \mathrm{~m}$ ) \\
C2 & middle-age coniferous forest (tree height 4-12 m) \\
C3 & mature coniferous forest (tree height $\geq 12 \mathrm{~m}$ ) \\
Altitude & mean altitude \\
Latitude & latitude of the centroid \\
Longitude & longitude of the centroid \\
\hline
\end{tabular}

Appendix S3: Table S1). We used 19 predictors related to land-use/cover and geographic/topographic information to build the SDMs. Land-use/cover variables were selected to describe the main land uses (intensive and extensive practices) and vegetation types (deciduous, coniferous, and mixed forest with three height classes, tree species tightly linked to water environments, regeneration, and nonproductive forest; see brief description and acronyms in Table 1). These land-use/cover variables consisted of the percentage of area that was occupied by each land-use/cover type within a radius of $500 \mathrm{~m}$ for each point count (Appendix S2: Figs. S2, S3). Latitude, longitude, and altitude were also included as predictors to account for geographic and topographic heterogeneity, thereby improving the predictive accuracy of the models (Table 1; Estrada et al. 2016). This set of predictors showed no evidence of collinearity (Pearson coefficient $|r|<0.4$; Dormann et al. 2013, see Appendix S2: Fig. S5). All models were trained using three widely used techniques: generalized linear models (GLM); generalized boosted models (GBM); and random forests (RF), which were available in the biomod 2 package of $\mathrm{R}$ (Thuiller et al. 2009). For each technique, we used the default settings in biomod2 because these settings are optimized for SDMs (see Thuiller et al. 2016).

The original bird data set was split into two subsets: $70 \%$ of the data was used for training the models and the remaining $30 \%$ for testing their performance (hereafter, crossvalidation). We randomly repeated this procedure 10 times to produce predictions that were independent of the training data (Fielding and Bell 1997). The area under the curve (AUC) of the receiver-operating characteristic (ROC) was considered as an estimate of model accuracy (Fielding and Bell 1997). This procedure was repeated for each species $(128$ species $\times 3$ modeling techniques $\times 10$ replicates $=$

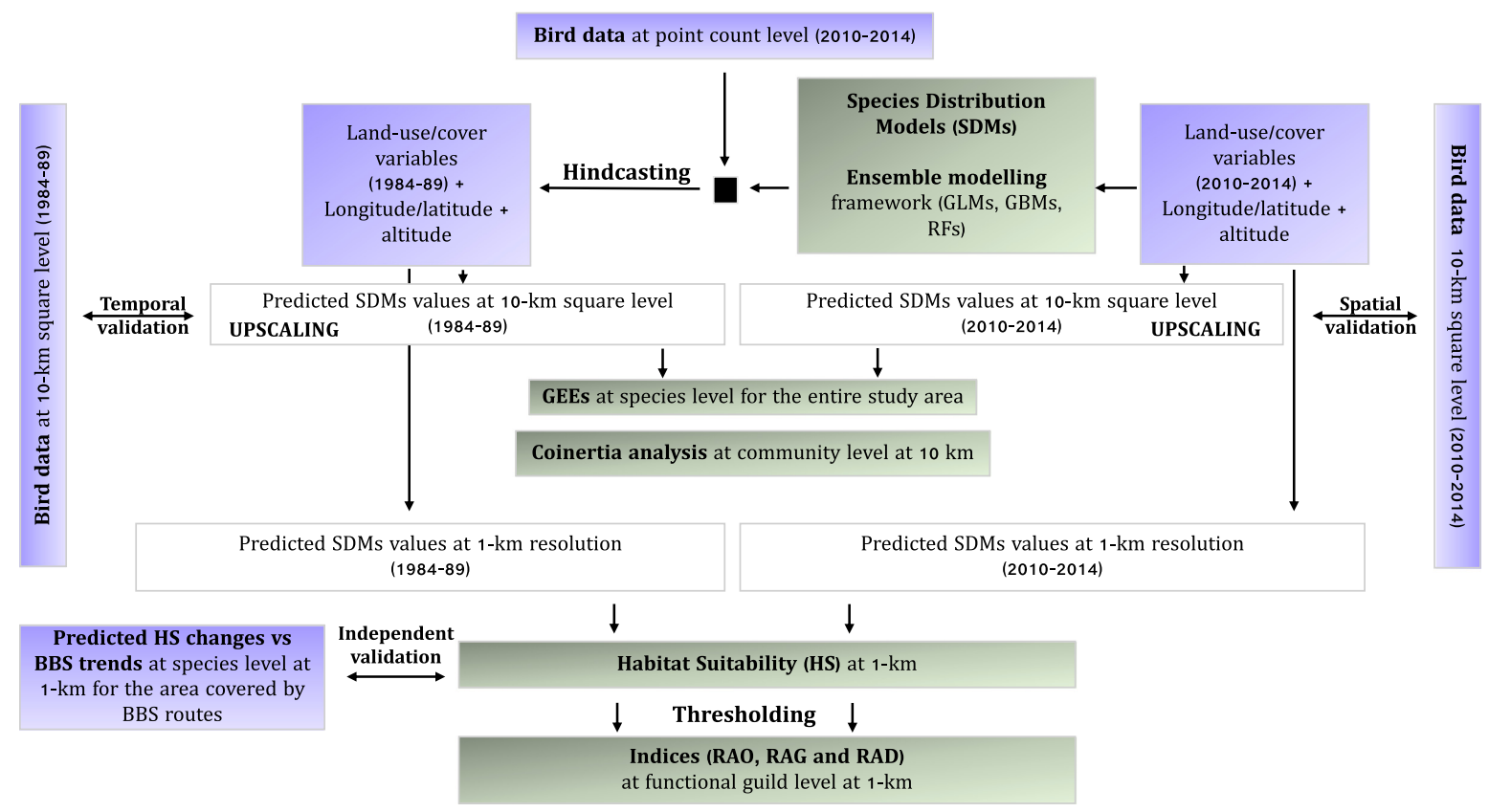

FIG. 2. Flow diagram of the modeling approach, validation steps, and change analysis (see Methods for a detailed description of each step). 
3,840 single-species models) (see Appendix S3: Table S1 for accuracy metrics of individual models). We applied an ensemble forecasting framework by averaging all single model projections (Araújo and New 2007), weighted using the AUC values (Marmion et al. 2009). Only models with AUC values above 0.7 were used in the ensemble procedure (see Appendix S3: Table S1 for accuracy of ensemble models). Although species distribution models may suffer from potential biases caused by imperfect detection (Kéry 2011, Lahoz-Monfort et al. 2014), we did not account for detection in our modeling approach because: (1) atlas data sets were not collected using the repeated temporal sample structure required for occupancy modeling, and (2) to date, ensemble modeling platforms (e.g., BIOMOD2) do not include algorithms to account for imperfect detection. In addition, (3) "occupancy," after accounting for imperfect detection, is a latent variable and therefore it is impossible to validate on independent data because the "true" state of independent data is unknown (Welsh et al. 2013).

The ensemble models were projected to the current landcover conditions (2010-2014) and to the land-cover conditions prevailing in 1984-1989 (hereafter, "hindcasting") at both square (10-km resolution) and grid cell level (1-km resolution). To evaluate spatiotemporal transferability of the ensemble models (i.e., our ability to extrapolate habitat suitability predictions in space and time), projections at the square level were tested (using AUC as an accuracy metric) against the observed bird data reported in the first and second Breeding Bird Atlases for Quebec, controlling for sampling effort by using only those squares with a minimum of $20 \mathrm{~h}$ of observation. The overall AUC values that were derived from each species within a given functional guild are shown in boxplots. The results were compared between functional guilds through a Wilcoxon signed-rank test for paired samples.

\section{Analysis of species distribution changes}

Change analyses were carried out over the entire study area of southern Quebec $\left(483,100 \mathrm{~km}^{2}\right)$ at two different spatial scales: (1) the square level, covering 4,014 UTM squares of $10-\mathrm{km}$ resolution; and (2) the grid cell level, encompassing 483,100 grid cells of 1-km resolution. Only bird species with AUC values higher than 0.7 in their spatial projections were considered in the change analysis (see list of species in Table 2). Further, the analyses at both spatial scales were conducted separately for the three dominant forest biomes in the study area to identify potential convergent or divergent trends between: (1) deciduous southern temperate forest; (2) boreal mixedwood forest; and (3) northerly coniferous forest. Each was subjected to different human land-use pressures over the last $30 \mathrm{yr}$ (Fig. 1).

\section{Change analysis at the 10-km square level}

We investigated temporal changes in species habitat suitability derived from SDMs at the square level in the entire study area (all squares together) between each atlas period (1984-1989 and 2010-2014) using generalized estimating equations (GEEs; R Core Team 2015). GEEs are an extension of generalized linear models (GLMs) for correlated data, which are suited to estimating the effect of a time-varying covariate (Lipsitz et al. 1994). We used species habitat suitability in the 4,014 UTM squares of $10-\mathrm{km}$ resolution in order to test for an effect of time period (1984-1989 and 2010-2014) on habitat suitability. To be conservative, we only considered significant changes that were associated with $P$ values that were $<0.01$.

We used a co-inertia analysis to examine the co-variation between the predicted SDMs values and land-cover variables at the square level, with the main emphasis on analyzing how much of the variation in SDMs values can be captured by the land-cover variables. Co-inertia analysis is a multivariate technique that is well suited for studying changes in species-environment relationships during two or more different time periods (e.g., see Sirami et al. 2007, Regos et al. 2016). It provides an ordination of $10 \mathrm{~km}$ square based upon the co-inertia weights of land-cover variables and another based on the co-inertia weights of the bird species. The bird data set comprised the habitat suitability predicted from the SDMs for bird species in the 8,028 squares $(4,014$ squares that cover the entire study area $\times 2$ time periods). The land-cover type data set consisted of the percentage of area occupied by each land-cover category, for each of the 8,028 squares. These proportions were calculated within each $10-\mathrm{km}$ square. Each square was assigned to one of the 16 land-cover types with the greatest cover during the initial period, i.e., 1984-1989 (Table 1). We used a MonteCarlo test (with 999 random permutations) to assess the significance of the co-structure of the data tables (Borcard et al. 2011). Co-inertia analysis and Monte-Carlo tests were performed within the ade4 library of R (Dray and Dufour 2007, R Core Team 2015).

\section{Change analysis at the 1-km grid cell level}

The contribution of each land-cover type to net change (i.e., conversion from one land-cover type to another) was estimated through a transition matrix obtained by crosstabulation of the land-use/cover maps. Transition matrices were computed with the $\mathrm{R}$ package lulcc v.1.0.2 (Moulds 2017) and visualized through a circular plot performed with the circlize R package (Gu 2014, R Core Team 2015), while net changes were represented through bar plots.

To quantify the changes in species habitat suitability and habitat spatial distributions at the grid cell level (i.e., 1-km resolution), we estimated the percentage of change between 1984-1989 and 2010-2014 using: (1) habitat suitability values, i.e., continuous values predicted from SDMs; and (2) habitat distributional range, i.e., after applying a threshold to convert continuous to binary values. Continuous habitat suitability predictions that were derived from the ensemble models were converted into binary presence-absence values by using a threshold maximizing the percentage presence that was correctly predicted (i.e., sensitivity) and the percentage absence that was correctly predicted (i.e., specificity). This threshold therefore minimizes the difference between sensitivity and specificity (Thuiller et al. 2003). To analyze the spatiotemporal dynamics of the habitat distributional range, we also calculated (3) the amount of overlap; (4) generation; and (5) disappearance of distribution area between both periods. For this purpose, we applied three 
TABLE 2. Change in habitat suitability (HS) derived from the SDMs for each bird species between 1984-1989 and 2010-2014 at the square level in relation to the values predicted for 1984-1989; and long-term trends from changes North American Breeding Bird Survey (BBS) data.

\begin{tabular}{|c|c|c|c|c|c|c|c|}
\hline \multirow[b]{2}{*}{ Scientific name } & \multirow[b]{2}{*}{ Common name } & \multicolumn{3}{|c|}{ Change from SDMs } & \multicolumn{3}{|c|}{ Change from BBS } \\
\hline & & $P$ & $\begin{array}{l}\text { Trend } \\
\text { GEE }\end{array}$ & $\begin{array}{c}\text { Change } \\
\text { HS }\end{array}$ & $\begin{array}{c}\text { Change } \\
\text { BBS }\end{array}$ & $\begin{array}{l}\text { Trend } \\
\text { BBS }\end{array}$ & $\begin{array}{l}\text { Reliability } \\
\text { BBS }\end{array}$ \\
\hline Dolichonyx oryzivorus & Bobolink & $<0.0001$ & decreasing & $-24,49$ & $-4,25$ & decreasing & high \\
\hline Passerculus sandwichensis & Savannah Sparrow & $<0.0001$ & decreasing & $-21,97$ & $-2,09$ & stable & low \\
\hline Sturnella magna & Eastern Meadowlark & $<0.0001$ & decreasing & $-14,84$ & $-5,29$ & decreasing & medium \\
\hline Hirundo rustica & Barn Swallow & $<0.0001$ & decreasing & $-14,55$ & $-5,36$ & decreasing & high \\
\hline Charadrius vociferus & Killdeer & $<0.0001$ & decreasing & $-11,67$ & $-4,43$ & decreasing & high \\
\hline Passer domesticus & House Sparrow & 0.0006 & decreasing & $-11,33$ & $-4,91$ & decreasing & high \\
\hline Columba livia & Rock Pigeon (Feral Pigeon) & $<0.0001$ & decreasing & $-10,92$ & 2,30 & increasing & high \\
\hline Melospiza melodia & Song Sparrow & $<0.0001$ & decreasing & $-9,25$ & $-1,08$ & decreasing & high \\
\hline Larus delawarensis & Ring-billed Gull & 0.0013 & decreasing & $-7,46$ & 4,50 & stable & low \\
\hline Cathartes aura & Turkey Vulture & $<0.0001$ & decreasing & $-7,01$ & 9,92 & increasing & medium \\
\hline $\begin{array}{l}\text { Coccyzus } \\
\text { erythropthalmus }\end{array}$ & Black-billed Cuckoo & 0.0001 & decreasing & $-6,22$ & $-0,37$ & stable & low \\
\hline Bartramia longicauda & Upland Sandpiper & $<0.0001$ & decreasing & $-6,19$ & $-1,69$ & stable & medium \\
\hline Quiscalus quiscula & Common Grackle & 0.0002 & decreasing & $-5,91$ & $-0,35$ & stable & high \\
\hline Circus hudsonius & Northern Harrier & $<0.0001$ & decreasing & $-5,40$ & $-0,92$ & stable & medium \\
\hline Spinus tristis & American Goldfinch & 0.0040 & decreasing & $-5,02$ & 0,57 & stable & high \\
\hline Falco sparverius & American Kestrel & $<0.0001$ & decreasing & $-5,00$ & $-1,13$ & stable & medium \\
\hline Setophaga petechia & Yellow Warbler & 0.0098 & decreasing & $-4,93$ & $-1,04$ & stable & low \\
\hline Corvus brachyrhynchos & American Crow & 0.0068 & decreasing & $-4,56$ & 0,52 & stable & medium \\
\hline Sayornis phoebe & Eastern Phoebe & 0.0753 & stable & $-4,36$ & $-0,17$ & stable & medium \\
\hline Petrochelidon pyrrhonota & Cliff Swallow & $<0.0001$ & decreasing & $-4,21$ & $-3,18$ & stable & medium \\
\hline Molothrus ater & Brown-headed Cowbird & 0.1389 & stable & $-4,03$ & $-5,90$ & decreasing & high \\
\hline Chaetura pelagica & Chimney Swift & 0.0004 & decreasing & $-3,68$ & $-2,89$ & decreasing & medium \\
\hline Phalacrocorax auritus & Double-crested Cormorant & 0.0072 & decreasing & $-2,95$ & 3,81 & increasing & low \\
\hline Picoides arcticus & Black-backed Woodpecker & 0.0233 & stable & $-2,84$ & 1,32 & stable & low \\
\hline Sialia sialis & Eastern Bluebird & 0.0264 & stable & $-2,68$ & 1,74 & stable & medium \\
\hline Tyrannus tyrannus & Eastern Kingbird & 0.2817 & stable & $-2,40$ & $-3,83$ & decreasing & high \\
\hline Melospiza lincolnii & Lincoln's Sparrow & 0.0643 & stable & $-2,34$ & $-0,68$ & stable & low \\
\hline Spizella passerina & Chipping Sparrow & 0.1610 & stable & $-2,14$ & $-1,43$ & stable & medium \\
\hline Zenaida macroura & Mourning Dove & 0.3266 & stable & $-2,13$ & 3,38 & increasing & high \\
\hline Larus argentatus & Herring Gull & 0.1744 & stable & $-2,11$ & $-1,94$ & stable & low \\
\hline Catharus fuscescens & Veery & 0.2261 & stable & $-1,94$ & 0,50 & stable & high \\
\hline Junco hyemalis & Dark-eyed Junco & 0.1730 & stable & $-1,76$ & $-0,02$ & stable & low \\
\hline Spinus pinus & Pine Siskin & 0.1148 & stable & $-1,70$ & $-0,98$ & stable & low \\
\hline Lophodytes cucullatus & Hooded Merganser & 0.1632 & stable & $-1,69$ & 6,03 & increasing & low \\
\hline Setophaga pensylvanica & Chestnut-sided Warbler & 0.2307 & stable & $-1,66$ & 0,33 & stable & high \\
\hline Passerina cyanea & Indigo Bunting & 0.5731 & stable & $-1,36$ & 1,83 & increasing & high \\
\hline Vireo gilvus & Warbling Vireo & 0.6558 & stable & $-1,35$ & 0,47 & stable & high \\
\hline Mergus merganser & Common Merganser & 0.3868 & stable & $-0,73$ & 1,41 & stable & low \\
\hline Icterus galbula & Baltimore Oriole & 0.8178 & stable & $-0,73$ & $-2,95$ & decreasing & high \\
\hline Sphyrapicus varius & Yellow-bellied Sapsucker & 0.4989 & stable & $-0,70$ & 2,96 & increasing & high \\
\hline Larus marinus & Great Black-backed Gull & 0.6393 & stable & $-0,63$ & $-1,74$ & stable & low \\
\hline Anas platyrhynchos & Mallard & 0.6836 & stable & $-0,60$ & 2,66 & stable & low \\
\hline Geothlypis trichas & Common Yellowthroat & 0.7095 & stable & $-0,32$ & $-1,46$ & decreasing & medium \\
\hline Empidonax traillii & Willow Flycatcher & 0.8931 & stable & $-0,20$ & 2,53 & stable & low \\
\hline Loxia leucoptera & White-winged Crossbill & 0.8188 & stable & 0,28 & 4 & increasing & low \\
\hline Poecile hudsonicus & Boreal Chickadee & 0.5275 & stable & 0,76 & $-0,63$ & stable & low \\
\hline Gavia immer & Common Loon & 0.3255 & stable & 0,78 & 1,72 & stable & medium \\
\hline Bucephala clangula & Common Goldeneye & 0.3123 & stable & 0,79 & 0,87 & stable & low \\
\hline Vireo solitarius & Blue-headed Vireo & 0.3816 & stable & 0,79 & 5,43 & increasing & medium \\
\hline Pheucticus ludovicianus & Rose-breasted Grosbeak & 0.6488 & stable & 0,83 & $-1,68$ & stable & high \\
\hline Troglodytes aedon & House Wren & 0.8042 & stable & 0,84 & $-0,46$ & stable & high \\
\hline Pinicola enucleator & Pine Grosbeak & 0.5000 & stable & 1,07 & NA & na & na \\
\hline Cyanocitta cristata & Blue Jay & 0.5489 & stable & 1,07 & 1,60 & increasing & high \\
\hline Haemorhous mexicanus & House Finch & 0.5050 & stable & 1,19 & 1,86 & stable & low \\
\hline Falcipennis canadensis & Spruce Grouse & 0.2880 & stable & 1,29 & 6,92 & increasing & low \\
\hline
\end{tabular}


TABLE 2. (Continued)

\begin{tabular}{|c|c|c|c|c|c|c|c|}
\hline \multirow[b]{2}{*}{ Scientific name } & \multirow[b]{2}{*}{ Common name } & \multicolumn{3}{|c|}{ Change from SDMs } & \multicolumn{3}{|c|}{ Change from BBS } \\
\hline & & $P$ & $\begin{array}{l}\text { Trend } \\
\text { GEE }\end{array}$ & $\begin{array}{c}\text { Change } \\
\text { HS }\end{array}$ & $\begin{array}{c}\text { Change } \\
\text { BBS }\end{array}$ & $\begin{array}{l}\text { Trend } \\
\text { BBS }\end{array}$ & $\begin{array}{l}\text { Reliability } \\
\text { BBS }\end{array}$ \\
\hline $\begin{array}{l}\text { Coccothraustes } \\
\text { vespertinus }\end{array}$ & Evening Grosbeak & 0.2311 & stable & 1,33 & $-5,57$ & decreasing & medium \\
\hline Regulus calendula & Ruby-crowned Kinglet & 0.2156 & stable & 1,44 & 2,55 & increasing & low \\
\hline Setophaga coronata & Yellow-rumped Warbler & 0.0434 & stable & 1,67 & 0,78 & stable & low \\
\hline Oreothlypis peregrina & Tennessee Warbler & 0.2765 & stable & 1,77 & 0,31 & stable & low \\
\hline Troglodytes hiemalis & Winter Wren & 0.0258 & stable & 1,88 & 0,80 & stable & medium \\
\hline Setophaga caerulescens & Black-throated Blue Warbler & 0.2487 & stable & 1,93 & 3,51 & increasing & high \\
\hline Vireo olivaceus & Red-eyed Vireo & 0.0867 & stable & 2,02 & 1,63 & increasing & high \\
\hline Euphagus carolinus & Rusty Blackbird & 0.1530 & stable & 2,14 & $-2,70$ & stable & low \\
\hline Setophaga virens & $\begin{array}{l}\text { Black-throated Green } \\
\text { Warbler }\end{array}$ & 0.0680 & stable & 2,22 & 1,94 & increasing & medium \\
\hline Setophaga tigrina & Cape May Warbler & 0.0623 & stable & 2,32 & 2,66 & stable & low \\
\hline Aix sponsa & Wood Duck & 0.0868 & stable & 2,45 & 2,80 & stable & low \\
\hline Catharus ustulatus & Swainson's Thrush & 0.0037 & increasing & 2,68 & $-0,18$ & stable & low \\
\hline Setophaga americana & Northern Parula & 0.1095 & stable & 2,74 & 8,44 & increasing & high \\
\hline Setophaga magnolia & Magnolia Warbler & 0.0003 & increasing & 2,86 & 2,85 & increasing & medium \\
\hline Contopus virens & Eastern Wood-Pewee & 0.1782 & stable & 2,86 & $-3,70$ & decreasing & high \\
\hline Mniotilta varia & Black-and-white Warbler & 0.0136 & stable & 2,93 & 0,89 & stable & high \\
\hline Sitta carolinensis & White-breasted Nuthatch & 0.1910 & stable & 2,94 & 0,36 & stable & medium \\
\hline Vireo philadelphicus & Philadelphia Vireo & 0.0134 & stable & 2,97 & 4,13 & increasing & low \\
\hline Eremophila alpestris & Horned Lark & 0.0002 & increasing & 3,11 & $-7,10$ & decreasing & medium \\
\hline Passerella iliaca & Fox Sparrow & 0.1177 & stable & 3,25 & 3,82 & increasing & low \\
\hline Cardellina pusilla & Wilson's Warbler & 0.0230 & stable & 3,36 & $-0,61$ & stable & low \\
\hline Empidonax flaviventris & Yellow-bellied Flycatcher & 0.0032 & increasing & 3,50 & 5,23 & stable & low \\
\hline Poecile atricapillus & Black-capped Chickadee & 0.0017 & increasing & 4,17 & 3,10 & increasing & high \\
\hline Setophaga castanea & Bay-breasted Warbler & 0.0032 & increasing & 4,17 & 2,74 & stable & medium \\
\hline Cardellina canadensis & Canada Warbler & 0.0002 & increasing & 4,39 & $-3,10$ & decreasing & medium \\
\hline Seiurus aurocapilla & Ovenbird & 0.0042 & increasing & 4,47 & 0,65 & stable & high \\
\hline Myiarchus crinitus & Great Crested Flycatcher & 0.0801 & stable & 5,10 & $-1,56$ & decreasing & high \\
\hline Setophaga fusca & Blackburnian Warbler & 0.0008 & increasing & 5,20 & 1,77 & increasing & high \\
\hline Setophaga pinus & Pine Warbler & 0.0024 & increasing & 6,11 & 4,58 & increasing & medium \\
\hline Piranga olivacea & Scarlet Tanager & 0.0049 & increasing & 6,48 & $-0,78$ & stable & high \\
\hline Buteo lineatus & Red-shouldered Hawk & $<0.0001$ & increasing & 7,10 & 1,55 & stable & medium \\
\hline Hylocichla mustelina & Wood Thrush & 0.0001 & increasing & 9,36 & $-5,19$ & decreasing & medium \\
\hline Pooecetes gramineus & Vesper Sparrow & $<0.0001$ & increasing & 11,45 & $-4,11$ & stable & low \\
\hline
\end{tabular}

Notes: $P$ values are from generalized estimating equations (GEE) analysis. Changes are considered significant when $P<0.01$. Species are ordered by increasing HS change. Reliability levels indicate the suitability (from low to high) of roadside survey routes from BBS program to monitor bird population for each species, according to expert opinion.

relative area indices (RAO, RAG, and RAD) that are well established in the landscape ecology literature (Maruca and Jacquez 2002, Regos et al. 2015), but have yet to be applied to ecological niche shift studies (but see Tapia et al. 2017). We calculated the Relative Area of Overlap (RAO), which was adapted from Maruca and Jacquez (2002), as:

$$
\mathrm{RAO} i-j=\frac{a(i \cap j)}{a(i \cup j)}
$$

where $a(i \cap j)$ is the area of intersection and $a(i \cup j)$ the union of species' distributions at the beginning (i) (1984$1989)$ and at the end (j) of the time interval (2010-2014). For distributions that do not intersect, the RAO will be zero while increasing values represent a greater overlap, up to a maximum value of one for perfectly overlapping distributional ranges (where $a(i \cap j)=a(i \cup j)$ ). Given that we expected to find spatiotemporal changes, especially in ecotonal areas, we also calculated relative area generation (RAG), which was adapted from Sirami et al. (2009) as

$$
\mathrm{RAG} i-j=\frac{a j-a(i \cap j)}{a(i \cup j)}
$$

where $a_{j}$ is the distribution area at the end of the time interval (2010-2014), and relative area disappearance (RAD):

$$
\mathrm{RAD} i-j=\frac{a i-a(i \cap j)}{a(i \cup j)}
$$

where $a_{i}$ is the distribution area at the beginning of the time interval (1984-1989).

We then conducted a comparison between temporal changes in species habitat suitability that were derived from 
SDMs and population trends of the North American Breeding Bird Survey (BBS) data from southern Quebec (1990-2014; Sauer et al. 2013) to determine if patterns of changes in habitat suitability were in line with long-term population trends. To do so, we defined a buffer of $40 \mathrm{~km}$ $(0.8 \mathrm{~km} \times 50$ stops $)$ around each starting point of each BBS route to delineate the area covered by BBS routes in southern Quebec $(N=211)$. Then, we computed the habitat suitability changes (i.e., continuous values predicted from SDMs) within the area covered by BBS routes. Finally, the habitat suitability changes at route level were compared with BBS trends through Pearson's correlation tests for the 30 species with "high reliability" BBS trends (see Table 2).

\section{RESULTS}

\section{Model performance and transferability}

The spatial distribution of all 128 species was well described within the calibration procedure at the point-count level (i.e., crossvalidation, $\mathrm{AUC}_{\text {mean }}=0.95 \pm 0.03$; Appendix S3: Table S1). The accuracy of the projections for the same period (2010-2014) at the square level (i.e., $10-\mathrm{km}$ spatial resolution) was also very high $\left(\mathrm{AUC}_{\text {mean }}=\right.$ $0.85 \pm 0.09$; Fig. 3), but slightly lower than within calibration procedure at the point-count level (Appendix S3: Table S1). The accuracy of the models that were projected at the square level, but hindcasted to past land-cover conditions in 1984-1989, was lower than within the calibration period, but still high $\left(\mathrm{AUC}_{\text {mean }}=0.77 \pm 0.10\right.$; Fig. 3, Appendix S3: Table S1), suggesting that our models were highly transferable in space and time (species habitat suitability maps at both spatial and temporal scales are available in Appendix S4). Species habitat suitability changes and distributional shifts between 1984-1989 and 2010-2014 periods were well predicted (AUC higher than 0.7 in both time periods) for $68 \%$ of a total of 128 species (i.e., 88 species; see Table 2 for a definitive list of 88 species finally considered for the subsequent change analysis).

Bird species associated with farmlands showed higher model transferability across periods $\left(\mathrm{AUC}_{\text {mean }}=0.87 \pm\right.$ $0.07)$ than forest-dwelling species $\left(\mathrm{AUC}_{\text {mean }}=0.81 \pm 0.10\right.$; $P_{\text {WILCOXON }}<0.001$; Fig. 3$)$. Species that were linked to intensive agriculture $\left(\mathrm{AUC}_{\text {mean }}=0.92 \pm 0.02\right)$ yielded higher model transferability than those that were linked to extensive practices $\left(\mathrm{AUC}_{\text {mean }}=0.86 \pm 0.07 ; \quad P_{\text {WILCOXON }}<\right.$ $0.05)$. Bird species that were linked with regeneration, and young and mature forests showed similar model transferability, although this was slightly lower for mature forest $\left(\mathrm{AUC}_{\text {mean }}=0.82 \pm 0.10 ; P_{\text {WILCOXON }}=0.68 ;\right.$ Fig. 3$)$. With respect to diet, granivorous species yielded the highest AUC values within and beyond the calibration period (Fig. 2). Temporal transferability was found to be slightly higher for tree-nesting $\left(\mathrm{AUC}_{\text {mean }}=0.82 \pm 0.1\right)$ than for cavity-nesting species $\left(\mathrm{AUC}_{\text {mean }}=0.80 \pm 0.1 ; P_{\mathrm{WILCOXON}}=0.25 ;\right.$ Fig. 3$)$. Models for water-dwelling species yielded the lowest model transferability $\left(\mathrm{AUC}_{\text {mean }}=0.74 \pm 0.1\right.$; Fig. 3$)$. Resident and migratory bird species showed similar model transferability, although this was slightly lower for short-distance migrants $\left(P_{\text {WILCOXON }}=0.29\right.$; Fig. 3$)$.

\section{Changes at the 10-km square level}

Four main assemblages of bird species were identified in the co-inertia analysis $\left(R V\right.$ coefficient $=0.51, P_{\text {MONTE- }}$ CARLO TEST $<0.001$ ), which were located within a gradient of deciduous to coniferous forest types (axis 1), and from closed to open habitats (axis 2; Fig. 4). The first species group was strongly associated with open habitats, in which some species were more closely correlated with nonproductive forest, while others were associated with perennial or annual agriculture (Fig. 4). The second group of species was mainly associated with deciduous forest (from young to mature forest; Fig. 4). Yet another group was correlated with mixed forest, whereas the last one was associated with coniferous forest. These forest-dwelling species showed different degrees of preference along a vegetation structure gradient ranging from young to mature stands (Fig. 4, and Appendix S1: Table S2). Also, more generalist species could be found somewhere in between in the ordination diagram (Fig. 4).

Among the 88 bird species that were considered in the analysis of temporal changes in habitat suitability, 14 species showed a significant increase $\left(P_{\mathrm{GEE}}<0.01\right)$ and 21 species showed a significant decrease between 1984-1989 and 2010-2014. The remaining 53 species were considered stable (Table 2). The co-inertia analysis showed that bird species for which the availability of suitable habitat decreased significantly over 1984-1989 and 2010-2014 were mostly associated with open habitats (i.e., intensive and extensive agricultural lands) and nonproductive forest, whereas bird species for which the availability of suitable habitat increased were mainly associated with mixed and deciduous forests. Bird species that were considered stable were equally distributed throughout these gradients (Fig. 4).

Land-cover scores within the $10 \mathrm{~km}$ squares appeared to have mainly declined along the vertical axis of the ordination diagram from agricultural and nonforest types to forested land along a gradient of afforestation (see "whole study area" in Fig. 4). Along the horizontal axis of the ordination diagram, the scores for squares that were initially dominated by mature and middle-age forest shifted toward different categories of young forest in structure, and toward mixed forest in composition (Fig. 4; e.g., deciduous forest mostly shifted to mixed forest, especially in boreal mixedwood forests, see Appendix S5: Fig. S1). Squares that were dominated by young forest shifted toward middle-aged and mature mixed forest (see, e.g., deciduous southern temperate forest in Appendix S5: Fig. S1). In southern Quebec, young forest types have markedly shifted to mature forest (see arrows in deciduous southern temperate forest in Appendix S5: Fig. S1). However, in the northerly coniferous forest biome, mature, and middle-aged coniferous forests have shifted to young forest stands and regeneration (Appendix S5: Fig. S1). Changes in bird assemblages follow patterns that were very similar to changes in land-cover types. Thus, the composition of bird species shifted along the vertical axis from assemblages with a higher proportion of species initially associated with open lands (i.e., agricultural and nonforest areas) to communities with species correlated with forested areas (Fig. 4). Bird assemblages that 

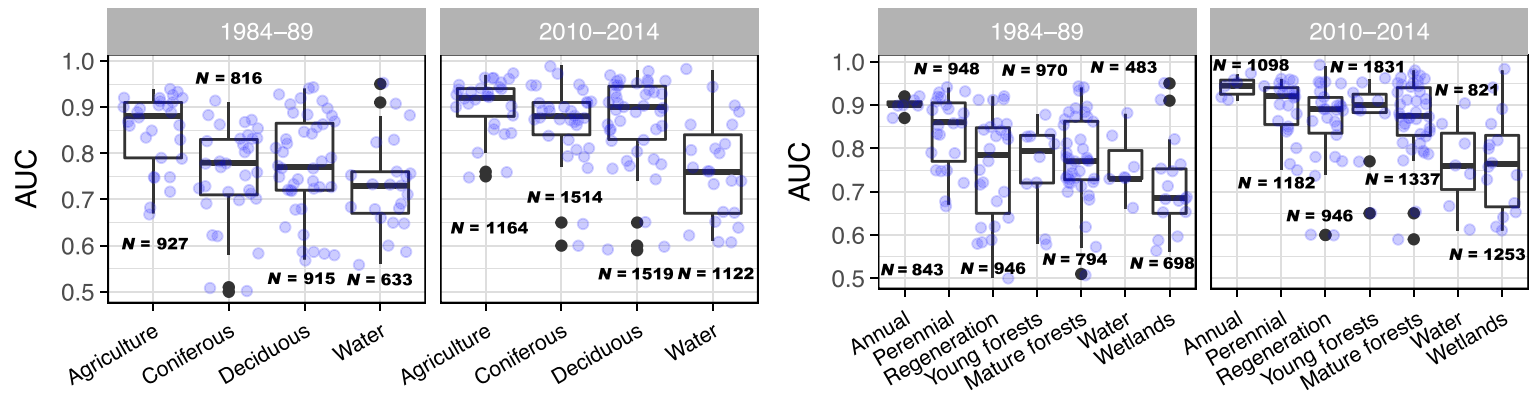

Composition

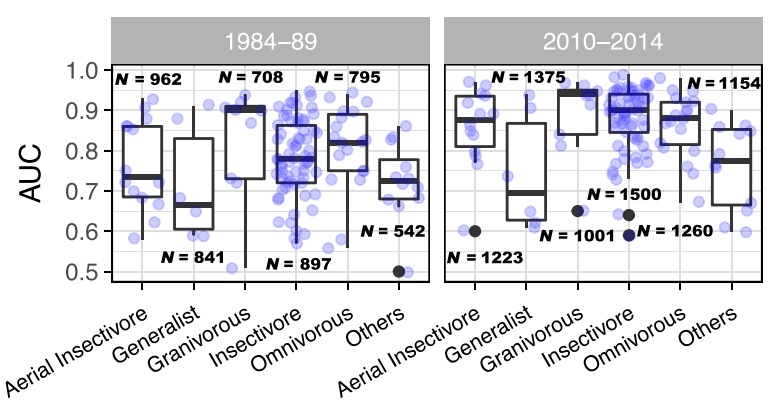

Feeding
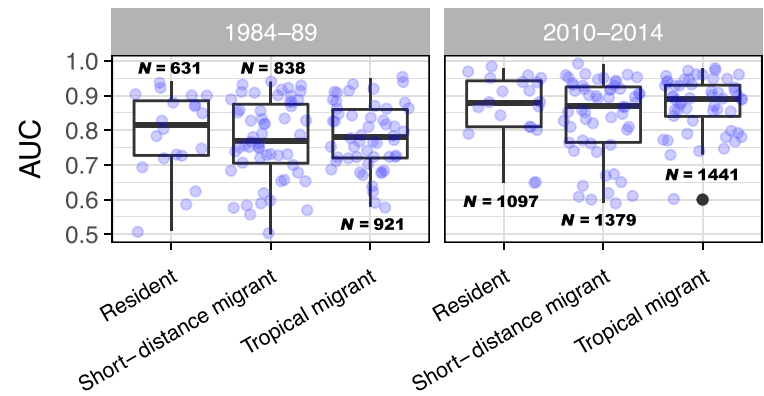

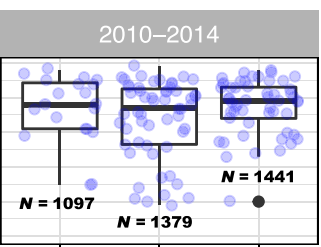

Migration
Structure

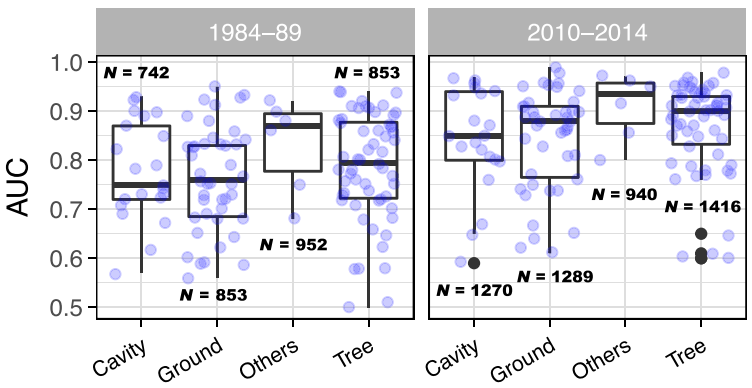

Nesting

FIG. 3. Model transferability: area under the curve (AUC) values of the projections at 10- $\mathrm{km}^{2}$ spatial resolution to present (2010-2014) and past land-use conditions (1984-1989) derived from the species distribution models (SDMs), grouped by functional traits. For all box plots, the lower and upper whiskers are the 5th and 95th percentiles; the hinges (edges of the box) are the 25th and 75th percentiles; the black line is the 50th percentile (median) values across species within a given functional trait. $N$ values indicates the average of presences for species with the same functional traits for each atlas period.

were associated with mature and middle-age forest shifted along the horizontal axis toward communities that were associated with young forest, and from deciduous to mixed forest (Fig. 4). The bird species have also shifted from assemblages of species that are linked with coniferous forest toward assemblages that are dominated by species associated with young coniferous forest and regeneration (Fig. 4), especially in northerly coniferous forest (Appendix S5: Fig. S1).

\section{Changes at the 1-km grid cell level}

The land-use/cover change analysis showed that the management of agriculture lands has strongly shifted from extensive (i.e., perennial agriculture) to more intensive use (i.e., annual agriculture) between 1984-1989 and 2010-2014 (see lines connecting perennial with annual agriculture in
Fig. 5). Overall, young and middle-aged forests have increased in spatial extent (despite their large turnover, see Fig. 5), whereas mature forests decreased (e.g., see lines going from mature coniferous forest to young, middle-age coniferous forest, and regeneration in Fig. 5), except for mature mixed forests. In fact, mixed forests have increased over the last $30 \mathrm{yr}$ for all structural types (from young to mature; Fig. 5).

Overall, the availability of habitats with suitable conditions for bird species that were linked to agricultural lands decreased (mean of $-6.89 \%$ ), which has led to important reductions in their initial habitat distributional range in all forest biomes (mean of $-10.45 \%$; Fig. 6). Species that are associated with agricultural areas under extensive use have suffered larger reductions in their initial habitat distribution (mean $\mathrm{RAD}_{\text {PE_AGRI }}=0.28 \pm 0.12$; Fig. 6 ) than those that are adapted to intensively managed agricultural areas (mean 


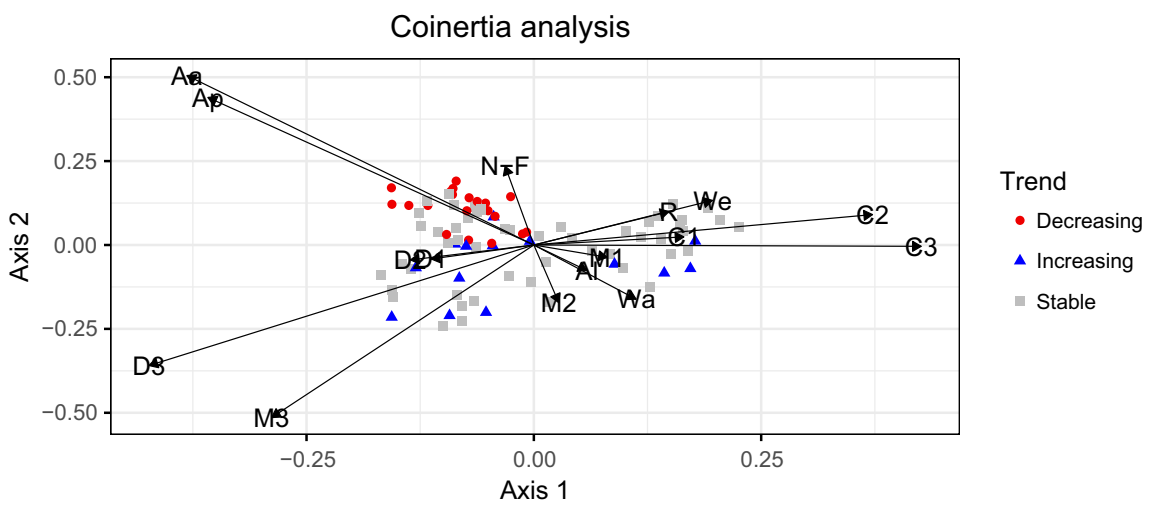

Whole study area
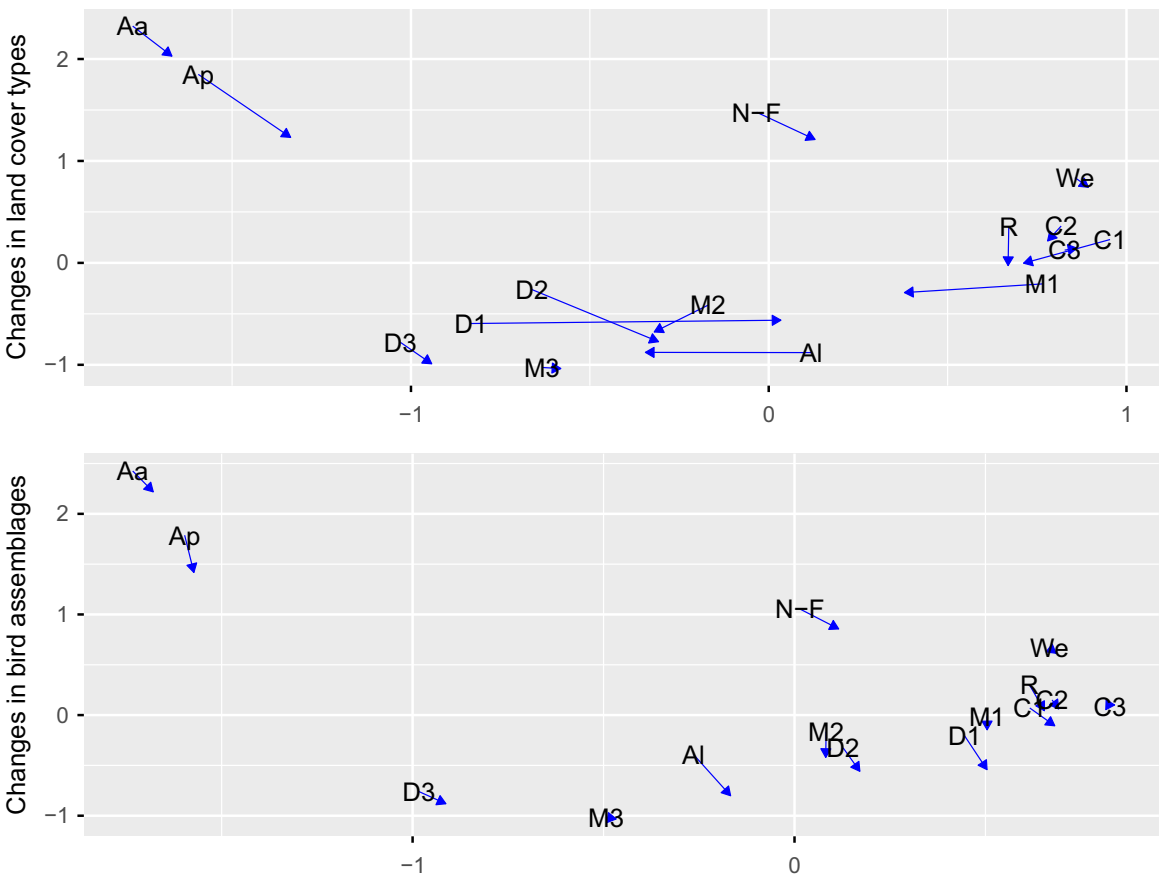

FIG. 4. Coinertia analysis: scores for bird species according to land-cover types on the axis 1 and axis 2 co-inertia plane. Color refers to bird species with decreasing (red dots), increasing (blue triangles), or stable (gray rectangles) habitat suitabilities during the study period according to generalized estimating equations (GEE) analysis. Axis 1 and axis 2 of co-inertia analysis showing temporal shifts in composition and structure of the land-cover types, and breeding bird community composition: the panel for "changes in land-cover type" refers to temporal shifts in the position of 10-km squares on the axis 1 and 2 co-inertia plane, using land-cover type variable co-inertia weights (normalized scores of 10-km squares were averaged within each subset of squares that were assigned to a given land-cover type in 1984-1989); the base of the arrows represents the average scores of a sample in 1984-1989 and the heads represent the average scores in 2010-2014; each arrow is identified by the abbreviated name of the land-cover type, whereas the lower panel for "changes in bird assemblage" refers to bird assemblage temporal shifts in position of $10-\mathrm{km}$ squares on the axis 1 and 2 co-inertia plane, using bird species co-inertia weights (scores of $10-\mathrm{km}$ squares were averaged within each sample, as was the case for the analysis of land-cover types). Abbreviated names of land-cover types are shown in Table 1.

$\operatorname{RAD}_{\text {AN_AGRI }}=0.17 \pm 0.04$, Fig. 6). The northerly coniferous forest biome did not show such trends, given the marginal development of agriculture within this region (Appendix S5: Figs. S2, S3). In contrast, the availability and distribution range of suitable habitat for forest-dwelling bird species has increased (Fig. 6), especially for those that are associated with young forests in the deciduous southern temperate forest biome (mean of $32.03 \%$, Appendix S5: Figs. S2, S3). However, the distributional range of bird species that are linked to mature forest decreased in the northerly coniferous forest biome (mean of $-12.32 \%$,
Appendix S5: Figs. S2). Aerial insectivores, granivorous, and ground-nesting species were the most negatively affected by land-use change in terms of availability of suitable habitats and distribution (Fig. 6). Cavity-nesting species have also suffered substantial reductions of their habitat distribution (mean RAD $_{\text {CAVITY-NESTING }}=0.20 \pm 0.06$; Fig. 6), mainly in the northerly coniferous forest biome, where they lost $-19.16 \%$ of their initial range (Appendix S5: Fig. S2). Overall, the availability of suitable habitat conditions and the distributional range for migratory species have decreased over the past few decades (Fig. 6). 
a) Net changes

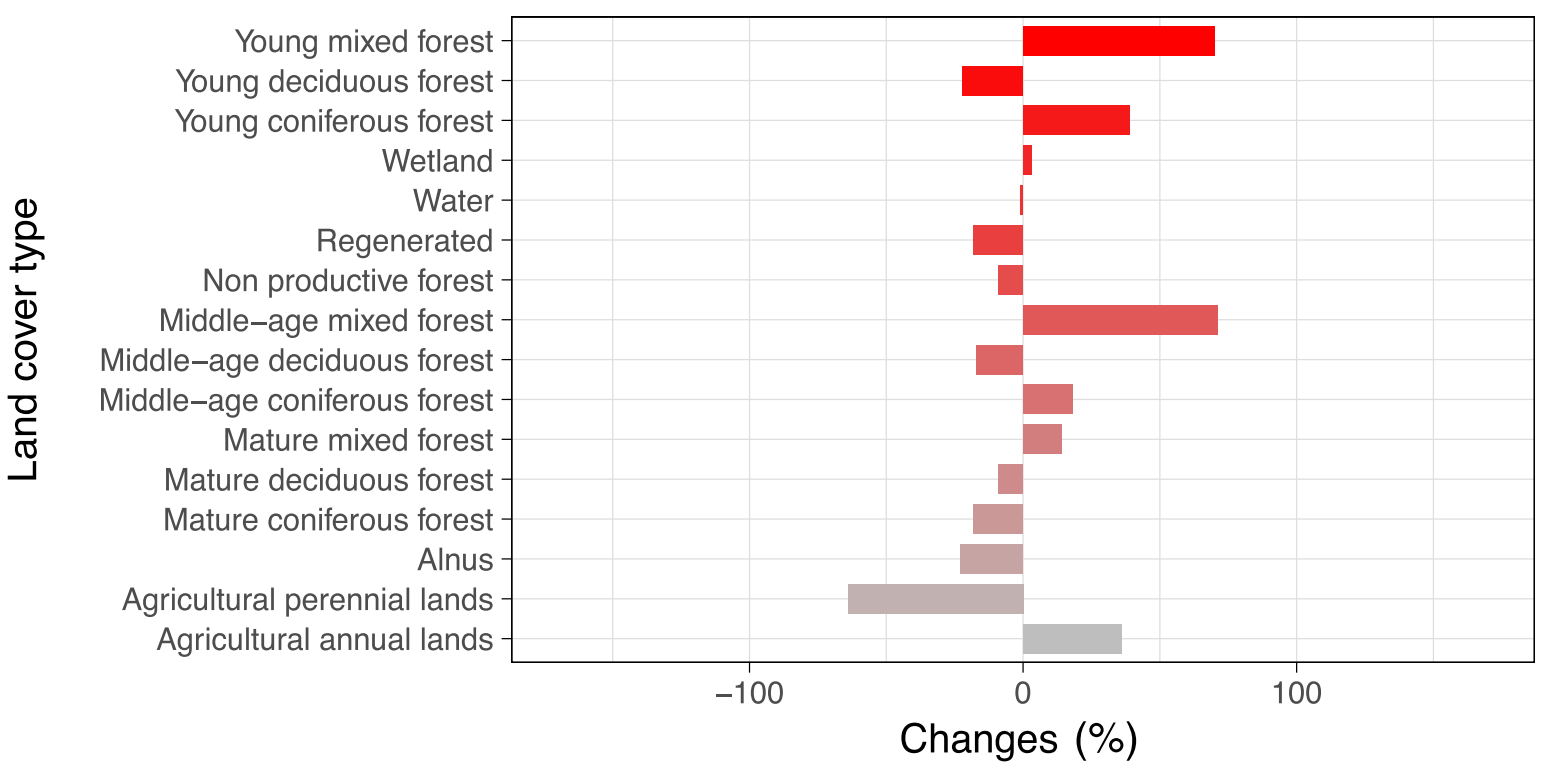

b) Land cover transitions

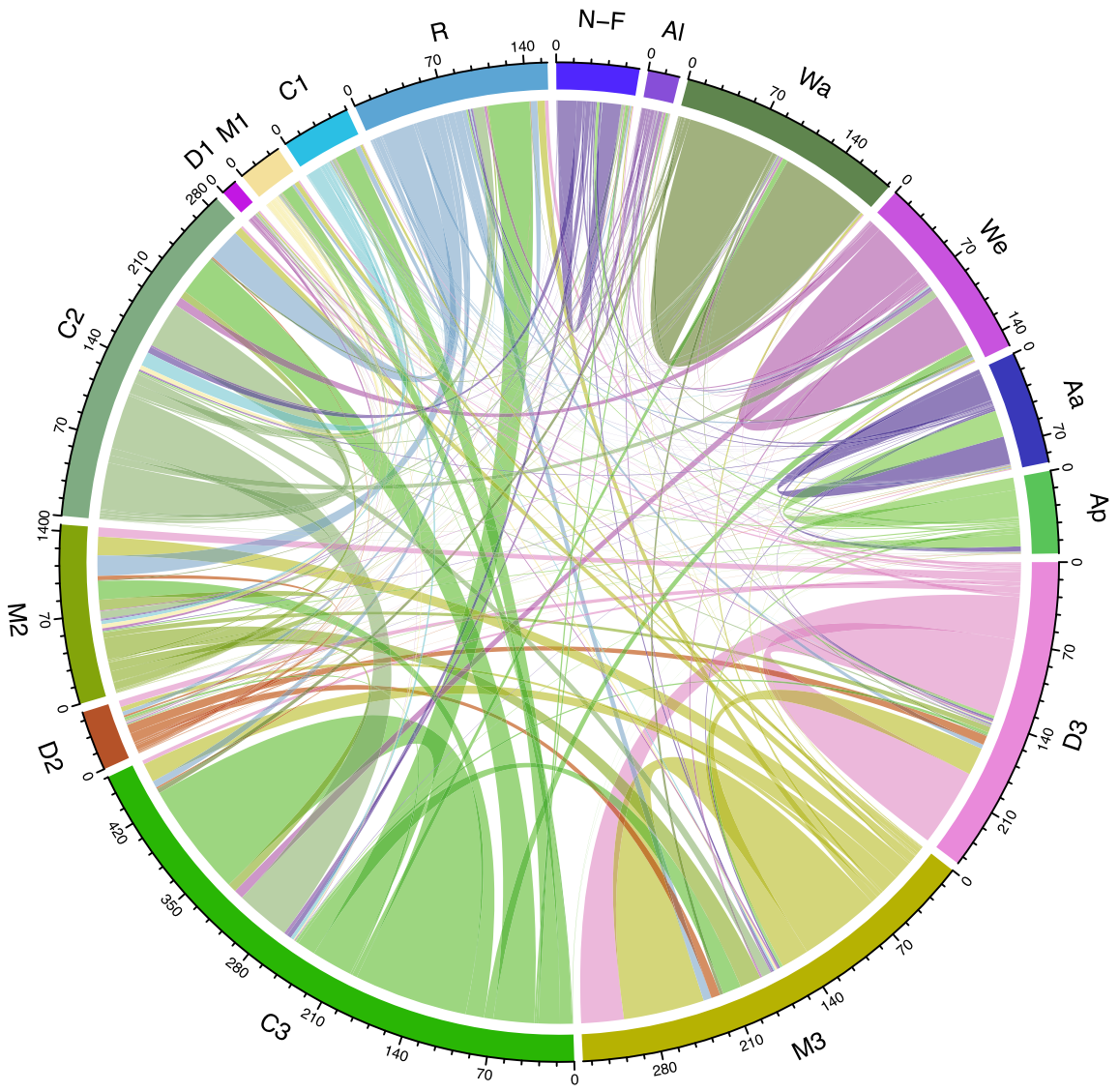

FIG. 5. Land-use/cover changes between 1984-1989 and 2010-2014: (a) net changes (\%) and (b) circular plot illustrating the land-cover type transitions, in million hectares (Mha). The size of the lines is proportional in width to the contribution of each land-cover type to the change. The colors refer to the land-cover types; abbreviated names are shown in Table 1.

These habitat suitability changes partially agreed with long-term trends that were estimated from the North American Breeding Bird Survey (BBS) data (1990-2014 period;
Sauer et al. 2013) from southern Quebec (Pearson coefficient $|r|=0.55, P=0.001$; see the 30 species with high reliability in Table 2). 

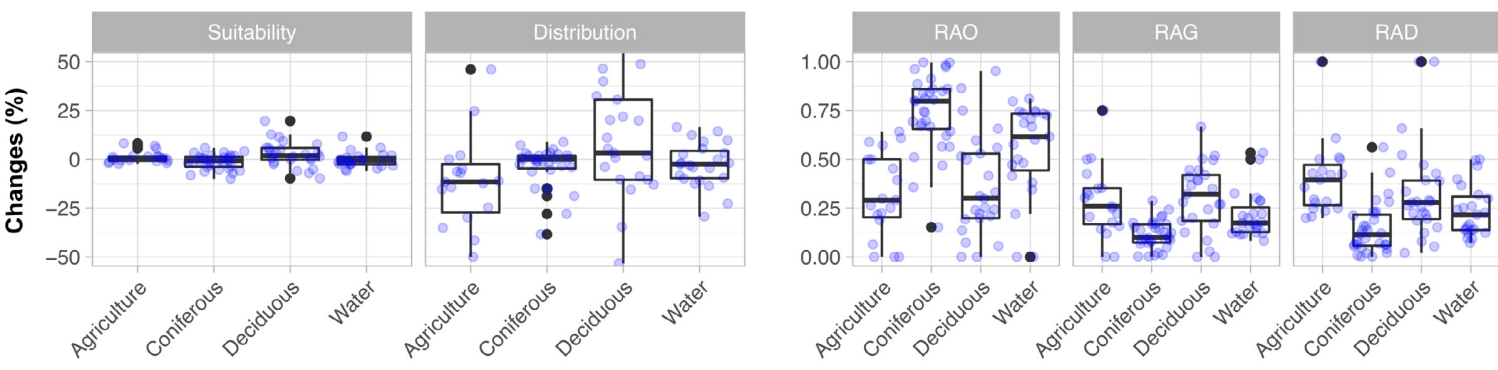

Composition
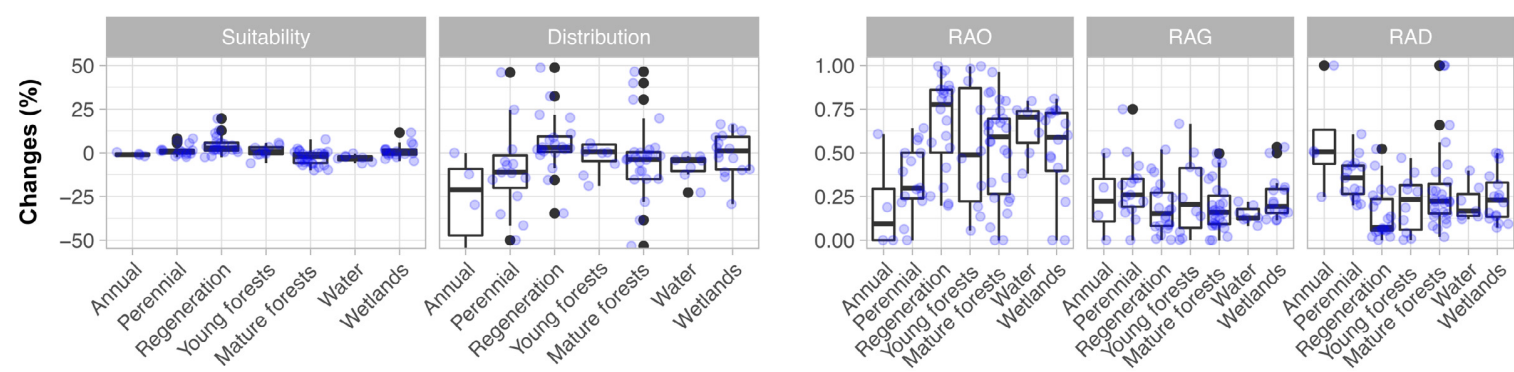

Structure
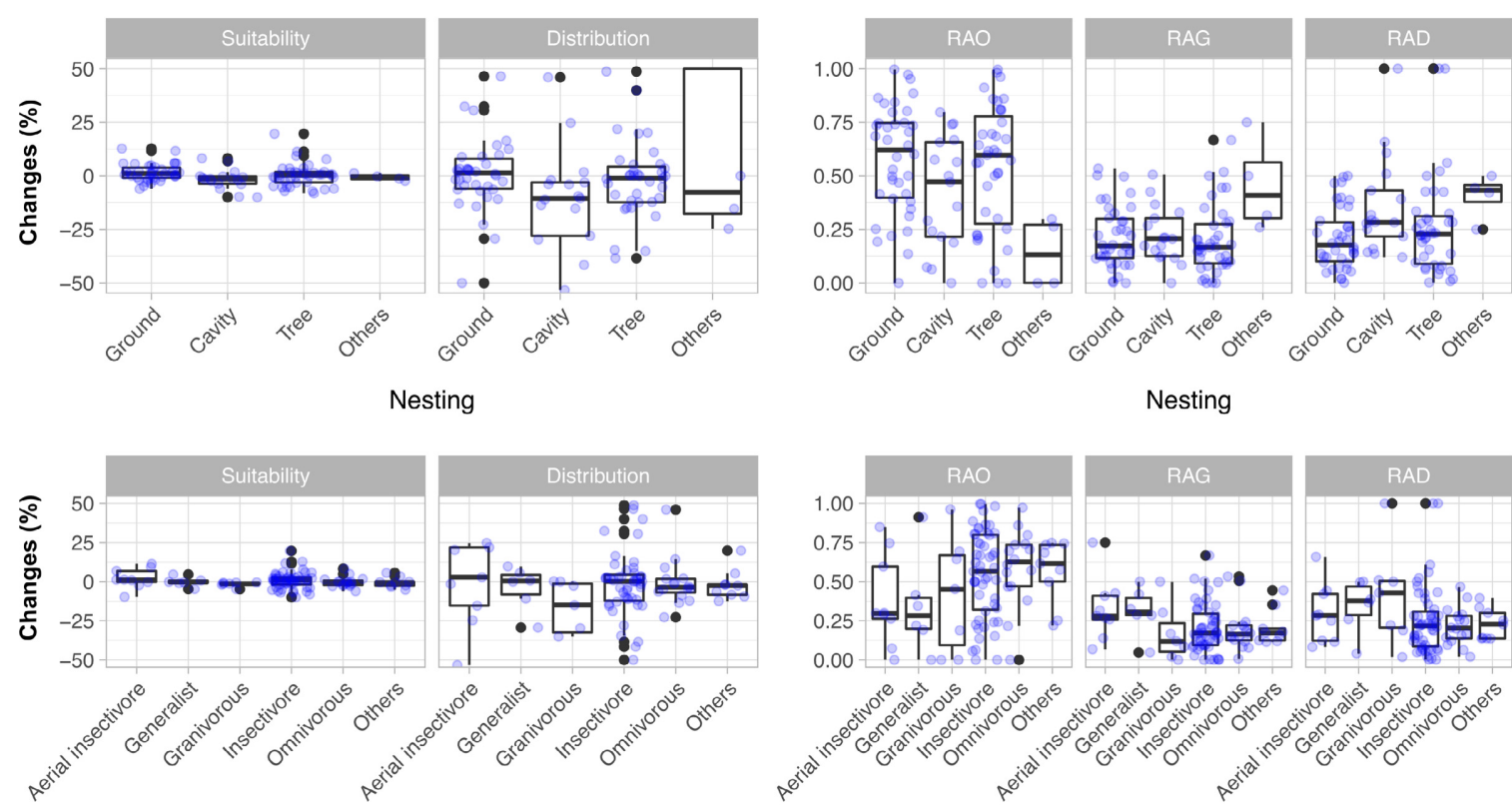

Feeding

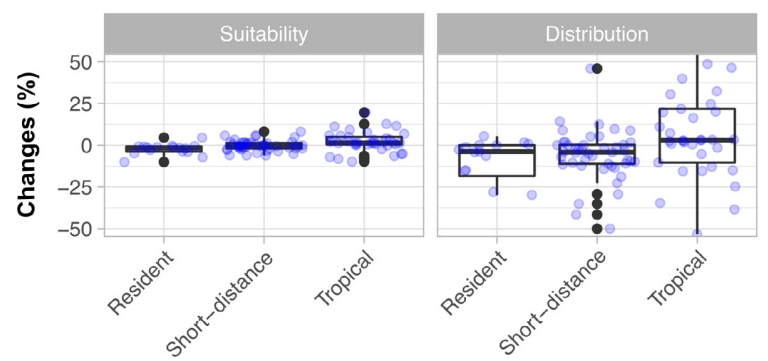

Migration

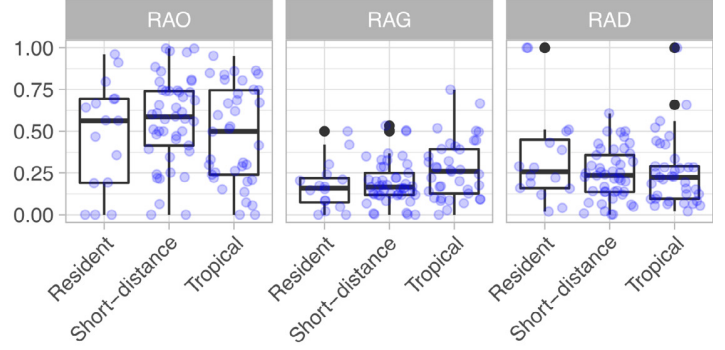

Migration

FIG. 6. Changes in habitat suitability and habitat distributional range and degree of overlap (RAO), generation (RAG), and disappearance (RAD) of habitat distributional ranges (i.e., after thresholding values of predicted SDM outputs) across bird species within each functional guild between 1984-1989 and 2010-2014 at the grid cell level for the whole study area. Blue dots indicate the value for each species. 


\section{Discussion}

Our attempts to predict the response of an entire bird community to land-use changes over the last $30 \mathrm{yr}$ by using species distribution models from a hindcasting perspective illustrates how global change research can leverage preexisting large spatial and temporal data sets such as Breeding Bird Atlas projects. In addition, it is one the few studies that examine the effects of specific functional and life-history traits on model transferability (but see Kharouba et al. 2009, Dobrowski et al. 2011, Wogan 2016). Overall, our models, relying exclusively upon coarse land-cover/use information, confirm the idea that land-use changes induced by human development are a key driver of change in bird populations. These findings highlight the utility of correlative SDMs to project past and likely future changes in species distributions at large spatial and temporal scales (Morán-Ordóñez et al. 2016, Wogan 2016). In the context of the ongoing global change, this study clearly supports the view to urgently incorporating land-use change into climate niche models that would improve our future biodiversity projections (Mantyka-Pringle et al. 2012, Sirami et al. 2017, Titeux et al. 2017). This is especially relevant given the interactive effects between climate and land-use change, and the important role that old-growth forest and their management may play to buffer the effect of climate change on forest ecosystems (Gauthier et al. 2015) and climate-sensitive bird populations (Betts et al. 2017, Regos et al. 2018).

\section{Land-use change and bird communities: impacts on ecosystem functions}

Our results showed clear correspondences between changes in vegetation structure and composition, and changes in bird assemblages (Fig. 4), which also points to land-use change induced by human development as a key driving force for bird communities in southern Quebec. These congruent patterns also indicate that at least for the 21 species for which the availability of suitable habitat decreased significantly over the last $30 \mathrm{yr}$ (Table 2), new opportunities for conservation can be identified from landuse management strategies that are alternatives to those that have been implemented so far (Imbeau et al. 2015). Our results showed that these declining bird species, such as Bobolink (Dolichonyx oryzivorus) and Eastern Meadowlark (Sturnella magna), were mostly associated with agricultural habitats (Appendix S5: Table S1). These changes can be related to land abandonment processes (i.e., conversion from agriculture to forest) and agricultural intensification (i.e., a shift from extensive to intensive agriculture; Fig. 5), as has been widely documented for southern Quebec (Jobin et al. 2010, 2014) and elsewhere in North America and Europe (for a review, see Reif 2013). However, these land-use changes were also found to be positive for some forest bird species, such as Ovenbird (Seiurus aurocapilla) and Blackcapped Chickadee (Poecile atricapillus), which are mainly associated with mixed and deciduous forests (Fig. 4). Therefore, land abandonment can provide a unique opportunity for the conservation of forest-dwelling bird species, as has been recently proposed for Europe (Navarro and Pereira 2012, Queiroz et al. 2014, Regos et al. 2016) and Quebec (Jobin et al. 2014).

The loss of bird species with particular traits might have effects on ecosystem functioning, with implications for the delivery of ecosystem services (Newbold et al. 2012). In this sense, our results have shown that aerial insectivores and granivores were the species most negatively affected by landuse change in terms of availability of suitable habitats and distribution (Fig. 6), with potential functional losses for pest control and seed dispersal services, respectively (Whelan et al. 2015). Yet, functionally similar species might respond differently to land-use change (cf. "response diversity" concept; Elmqvist et al. 2003). The loss of variability in responses among species within the same functional guild could increase the vulnerability and reduce the resilience of ecosystems to disturbance, mismanagement, and land degradation (Laliberté et al. 2010). In our case, insectivorous species were found to response very heterogeneously to the land-use changes (Fig. 6), with habitat suitability change that range from $-9.78 \%$ for the Chimney Swift (Chaetura pelagica) to $+3.53 \%$ for Magnolia Warbler (Setophaga magnolia) in northern coniferous forests, for example (Appendix S5: Table S1). Further, for primary cavity excavators such as woodpeckers, which are the key-hole-providers for cavity-nesting birds in mixedwood and coniferous forest biomes across North America (Martin et al. 2004, Drapeau et al. 2009b, Cooke and Hannon 2011, Ouellet-Lapointe et al. 2012), reduction of mature and old forest that harbor large and decaying trees suitable for excavation could have potential cascading effects on other cavity-dependent species (Kappes 1997). Our results indeed showed marked reductions in the spatial distribution of suitable habitats for cavity-nesting birds (Fig. 6), mainly in the northerly coniferous forests where they lost around 19\% of their initial habitat range between the two atlases (Appendix S5: Fig. S2). These findings are in line with previous research at more local scales, and clearly confirm that the cumulative effect of intensive logging and wildfires on mature and old forests in the boreal ecosystem may poses a threat to forest-specialist species (Drapeau et al. 2016), including cavity-nesting birds (Imbeau et al. 2001, Schmiegelow and Mönkkönen 2002). In the boreal forest, a shift from conventional even-aged management toward more ecosystem-based management practices that combines longer rotations, partial cutting (uneven-aged management), and increased retention of old trees and old forest patches in aggregated clear-cuts could benefit species sensitive to old forest cover (Drapeau et al. 2016), particularly cavity excavators (Edworthy et al. 2011, Ouellet-Lapointe et al. 2012).

\section{Model performance and transferability}

Not surprisingly, as observed in previous model transferability assessments (see Randin et al. 2006, Torres et al. 2015, Huang and Frimpong 2016, among others) our estimates of model performance that were obtained from crossvalidation procedures were much higher than those that were based upon temporally and spatially independent data (Appendix S3: Table S1). In fact, high discriminatory power within the calibration period did not guarantee good 
temporal transferability for all cases (e.g., see Whitethroated or Swamp Sparrow in Appendix S3: Table S1), which highlights the need for transferability assessments when there is interest in making inferences beyond the model calibration period (Wenger and Olden 2012). In the case of species that are associated with aquatic habitats and wetlands, their low transferability is likely explained by (1) our habitat resolution (14 ha), which lacks several finegrained habitat categories, such as highly dynamic beaver ponds ( $<8 \mathrm{ha})$, which were selected by several species in our study area (Lemelin et al. 2010), and (2) the sampling methodology, given that point counts is not the best survey method for obtaining reliable waterfowl distributional data. Nevertheless, our results suggest overall good model transferability (i.e., ability of our models to be generalized to other times and scales), given that they were able to accurately predict, both in space and time, the habitat suitability for 88 bird species, viz., $69 \%$ of the 128 modeled species (Fig. 3, Appendix S3: Table S1).

Despite good overall model transferability, habitat suitability changes that were predicted from SDMs between 1984 1989 and 2010-2014 only partially agreed with long-term trends reported by the North American Breeding Bird Survey (Pearson coefficient $|r|=0.55, P=0.001$; see the 30 species with high reliability in Table 2). This partial mismatch between our predicted breeding habitat suitability change and the observed population trends can be attributed to other factors, such as climate change (Gutiérrez-Illán et al. 2014), habitat changes in wintering areas or migration routes (Greenberg and Marra 2005), pesticides and their effects on prey availability (Goulson 2014), occurrence of insect outbreaks (such as spruce budworm in our study area) (Venier and Holmes 2010), diseases (caused by either invasive or native pathogens; LaDeau et al. 2007), or unmeasured habitat features (Krebs et al. 1999), among others. This mismatch also draws attention to the need for developing new measures of testing the ability of SDMs to predict past and likely future changes (e.g., Rapacciuolo et al. 2014). Moreover, the lack of repeated temporal sample structure in atlas data required for accounting statistically for biases related to imperfect detection is another additional source of variation (Kéry 2011, Lahoz-Monfort et al. 2014).

Specific ecological and life-history traits of species have a significant effect on model performance for different taxa (McPherson and Jetz 2007, Pöyry et al. 2008, Syphard and Franklin 2010), given that they are also good predictors of range shifts (MacLean and Beissinger 2017). Despite their relevance for forecasting global change responses, the role that is played by species traits in model transferability has been seldom evaluated, with just a few examples for butterflies, vascular plants, and birds (Kharouba et al. 2009, Dobrowski et al. 2011, Wogan 2016). In our case, species that are tied to agricultural lands yielded the highest model transferability (Fig. 3), which was likely due to both a high degree of habitat specialization and a restricted distributional range within southern Quebec (see Appendices S2 and S4; Wogan 2016). Species that are associated with agricultural areas under intensive use showed higher model transferability than under extensive management (Fig. 3), which sheds light on the relevance of accounting for changes in land use within, and not only between, certain types of land-cover (i.e., the intensity of land use) for biodiversity projections (Titeux et al. 2016b). Nevertheless, birds with preferences for mature forests, also often habitat-specialist species (e.g., woodpeckers), with narrower niche breadths, and which are a priori more predictable than species that are tightly linked to disturbance-dependent habitats (see Syphard and Franklin 2010, Dobrowski et al. 2011), showed slightly lower model transferability (Fig. 3). In this sense, the explicit consideration of ecologically meaningful processes for species (i.e., accumulating clearcutting and fire) when modeling species distributions might have improved the temporal transferability of our SDMs, as has been illustrated by Vallecillo et al. (2009) for fire-prone systems in Catalonia. Unfortunately, bird species associated with landcover typologies that aimed at representing these processes (i.e., regeneration and young forest classes) showed considerably lower accuracy when projected onto the initial landcover conditions (1984-1989) than onto the conditions that were prevalent during the calibration period (Fig. 3). This result highlights the difficulties of predicting habitat suitability through time for disturbance-dependent species (Nappi and Drapeau 2009, Vallecillo et al. 2009, Nappi et al. 2010). In this sense, more mechanistic or process-based approaches might help overcome modeling limitations related to species' dispersal ability or others important biotic factors that are not usually included in purely correlative SDMs, and thus improve spatial predictions and model transferability (Evans et al. 2018).

Overall, our results indicate that the temporal transferability of SDMs can depend upon specific functional and life-history traits (Fig. 3), which provides further evidence that species ecology is likely to affect the ability of models to predict bird distributions in space and time. However, we caution against the over-interpretation of our results given that environmental tolerance, physiological adaptation and life history tend to covary between trait groups (because of a possible lack of independence caused by bird phylogeny) (Bennett and Owens 2002). In this regard, future research combining trait-based approaches in light of the species evolutionary history could help to link niche modeling to other ecological disciplines including community, functional, and evolutionary ecology; and shed light on the processes driving bird communities, to ultimately improve predictions of global change impacts (Cavender-Bares et al. 2009).

\section{ACKNOWLEDGMENTS}

This work was partly funded by the NEWFORESTS (EU Seventh Framework Programme, PIRSES- GA-2013-612645) and FORESTCAST (CGL2014-59742) projects, as well as NSERC-discovery grants to P. Drapeau and L. Imbeau. A. Regos is funded by the Xunta de Galicia (post-doctoral fellowship ED481B2016/084$0)$. We thank the Regroupement Québec Oiseaux, the Canadian Wildlife Service of Environment Canada, and Bird Studies Canada for supplying Atlas data. We also thank the hundreds of participants who took part in the Atlas field campaigns, the Ministère des Forêts, de la Faune et des Parcs du Québec (MFFPQ) for the SIFORT IV, and W. F. J. Parsons for English editing.

\section{Literature Cited}

Araújo, M. B., and M. New. 2007. Ensemble forecasting of species distributions. Trends in Ecology and Evolution 22:42-47. 
Balmer, D. E., S. Gillings, B. Caffrey, R. L. Swann, I. S. Downie, and R. J. Fuller. 2013. Bird Atlas 2007-11: the breeding and wintering birds of Britain and Ireland. BTO Books, Thetford, UK.

Bennett, P. M., and I. P. F. Owens. 2002. Evolutionary ecology of birds: life histories, mating systems, and extinction. Oxford University Press, Oxford, UK.

Bergeron, Y., D. B. Irulappa Pillai Vijayakumar, H. Ouzennou, F. Raulier, A. Leduc, and S. Gauthier. 2017. Projections of future forest age class structure under the influence of fire and harvesting: implications for forest management in the boreal forest of eastern Canada. Forestry 90:485-495.

Betts, M. G., B. Phalan, S. J. K. Frey, J. S. Rousseau, and Z. Yang. 2017. Old-growth forests buffer climate-sensitive bird populations from warming. Diversity and Distributions 24(4):439-447.

Bibby, C. J., N. D. Burgess, and D. A. Hill. 1992. Bird census techniques. Cambridge University Press, Cambridge, UK.

Borcard, D., F. Gillet, and P. Legendre. 2011. Numerical ecology with R. Science+Business Media, New York, New York, USA.

Bouchard, M., and D. Pothier. 2011. Long-term influence of fire and harvesting on boreal forest age structure and forest composition in eastern Québec. Forest Ecology and Management 261:811-820.

Boucher, Y., M. Perrault-Hébert, R. Fournier, P. Drapeau, and I. Auger. 2017. Cumulative patterns of logging and fire (19402009): consequences on the structure of the eastern Canadian boreal forest. Landscape Ecology 32:361-375.

Brotons, L., S. Herrando, J. Estrada, V. Pedrocchi, and J. Martin. 2008. The Catalan Breeding Bird Atlas (CBBA): methodological aspects and ecological implications. Revista Catalana d'Ornithologia 24:118-137.

Cadman, M. D., P. F. Eagles, and F. M. Helleiner. 1987. Atlas of the breeding birds of Ontario. First edition. University of Waterloo Press, Waterloo, Ontario, Canada.

Cavender-Bares, J., K. H. Kozak, P. V. A. Fine, and S. W. Kembel 2009. The merging of community ecology and phylogenetic biology. Ecology Letters 12:693-715.

CBD. 2010. Global biodiversity outlook 3. Secretariat of the Convention on Biological Diversity, Montreal, Quebec, Canada. http://www.cbd.int/doc/publications/gbo/gbo3-final-en.pdf

Cooke, H. A., and S. J. Hannon. 2011. Do aggregated harvests with structural retention conserve the cavity web of old upland forest in the boreal plains? Forest Ecology and Management 261:662674.

De Cáceres, M., L. Brotons, N. Aquilué, and M.-J. Fortin. 2013. The combined effects of land-use legacies and novel fire regimes on bird distributions in the Mediterranean. Journal of Biogeography 40:1535-1547.

Diamond, S. E., A. M. Frame, R. A. Martin, and L. Buckley. 2011. Species' traits predict phenological responses to climate change in butterflies. Ecology 92:1005-1012.

Dobrowski, S. Z., J. H. Thorne, J. A. Greenberg, H. D. Safford, A. R. Mynsberge, S. M. Crimmins, and A. K. Swanson. 2011. Modeling plant ranges over 75 years of climate change in California, USA: temporal transferability and species traits. Ecological Monographs 81:241-257.

Donaldson, M. R., N. J. Burnett, D. C. Braun, C. D. Suski, S. G. Hinch, S. J. Cooke, and J. T. Kerr. 2016. Taxonomic bias and international biodiversity conservation research. Facets 1:105-113.

Dormann, C. F., et al. 2013. Collinearity: a review of methods to deal with it and a simulation study evaluating their performance. Ecography 36:027-046.

Drapeau, P., A. Leduc, J. Giroux, J. L. Savard, and W. L. Vickery. 2000. Landscape-scale disturbances and changes in bird communities of boreal mixedwood forests. Ecological Monographs 70:423-444.

Drapeau, P., A. Leduc, and Y. Bergeron. 2009a. Bridging ecosystem and multiple species approaches for setting conservation targets in managed boreal landscapes. Pages 129-160 in J.-A. Villard and B. Jonsson, editors. Setting conservation targets for managed forest landscapes. Cambridge University Press, Cambridge, UK.
Drapeau, P., A. Nappi, L. Imbeau, and M. Saint-Germain. $2009 b$. Standing deadwood for keystone bird species in the eastern boreal forest: managing for snag dynamics. Forestry Chronicle 85:227234.

Drapeau, P., M.-A. Villard, A. Leduc, and S. J. Hannon. 2016. Natural disturbance regimes as templates for the response of bird species assemblages to contemporary forest management. Diversity and Distributions 22:385-399.

Dray, S., and A. Dufour. 2007. The ade4 package: implementing the duality diagram for ecologists. Journal of Statistical Software 22:1-20.

Edworthy, A. B., M. C. Drever, and K. Martin. 2011. Woodpeckers increase in abundance but maintain fecundity in response to an outbreak of mountain pine bark beetles. Forest Ecology and Management 261:203-210.

Elmqvist, T., C. Folke, M. Nystrom, G. Peterson, J. Bengtsson, B. Walker, and J. Norberg. 2003. Response diversity, ecosystem change, and resilience. Frontiers in Ecology and the Environment 1:488.

Estrada, J., V. Pedrocchi, L. Brotons, and S. Herrando. 2004. Catalan breeding bird atlas (1999-2002). Institut Catala d'Ornitologia, Lynx, Barcelona, Spain.

Estrada, A., M. P. Delgado, B. Arroyo, J. Traba, and M. B. Morales. 2016. Forecasting large-scale habitat suitability of European bustards under climate change: the role of environmental and geographic variables. PLoS ONE 11:e0149810.

Evans, M. E. K., C. Merow, S. Record, S. M. McMahon, and B. J. Enquist. 2018. Toward process-based range modeling of many species. Trends in Ecology \& Evolution 31:860-871.

Fielding, A. H., and J. F. Bell. 1997. A review of methods for the assessment of prediction errors in conservation presence/absence models. Environmental Conservation 24:38-49.

Freemark, K. E., and H. G. Merriam. 1986. Importance of area and heterogeneity to bird assemblages in temperate forest fragments. Biological Conservation 36:115-141.

Gauthier, J., and Y. Aubry. 1996. The breeding birds of Québec: atlas of the breeding birds of southern Québec. Association Québécoise des Groupes D'Ornithologues. Canadian Wildlife Service, Environment Canada, Québec Region, Montreal, Quebec, Canada.

Gauthier, S., P. Bernier, T. Kuuluvainen, A. Z. Shvidenko, and D. G. Schepaschenko. 2015. Boreal forest health and global change. Science 349:819-822.

Gibbons, D. W., J. B. Reid, and R. A. Chapman. 1993. The new atlas of breeding birds in Britain and Ireland: 1988-1991. Academic Press, London, UK.

Gibson, L., et al. 2011. Primary forests are irreplaceable for sustaining tropical biodiversity. Nature 478:378-381.

Goulson, D. 2014. Pesticides linked to bird declines. Nature 511:295-296.

Greenberg, R., and P. P. Marra. 2005. Birds of two worlds: the ecology and evolution of migration. JHU Press, Baltimore, Maryland, USA.

Gu, Z. 2014. Circlize implements and enhances circular visualization in R. Bioinformatics 30:2811-2812.

Guisan, A., and N. E. Zimmermann. 2000. Predictive habitat distribution models in ecology. Ecological Modelling 135:147-186.

Gutiérrez-Illán, J., C. D. Thomas, J. A. Jones, W. K. Wong, S. M. Shirley, and M. G. Betts. 2014. Precipitation and winter temperature predict long-term range-scale abundance changes in Western North American birds. Global Change Biology 20:3351-3364.

Huang, J., and E. A. Frimpong. 2016. Limited transferability of stream-fish distribution models among river catchments: reasons and implications. Freshwater Biology 61:729-744.

Imbeau, L., M. Mönkkönen, and A. Desrochers. 2001. Long-term effects of forestry on birds of the eastern Canadian boreal forests: a comparison with Fennoscandia. Conservation Biology 15:11511162.

Imbeau, L., M.-H. St-Laurent, L. Marzell, and V. Brodeur. 2015. Current capacity to conduct ecologically sustainable forest management in northeastern Canada reveals challenges for 
conservation of biodiversity. Canadian Journal of Forest Research 45:567-578.

Isbell, F., et al. 2011. High plant diversity is needed to maintain ecosystem services. Nature 477:199-202.

Jenkins, C. N., S. L. Pimm, and L. N. Joppa. 2013. Global patterns of terrestrial vertebrate diversity and conservation. Proceedings of the National Academy of Sciences USA 110:E2602-E2610.

Jobin, B., J. Beaulieu, M. Grenier, L. Bélanger, C. Maisonneuve, D. Bordage, and B. Filion. 2003. Landscape changes and ecological studies in agricultural regions, Quebec, Canada. Landscape Ecology 18:575-590.

Jobin, B., C. Latendresse, M. Grenier, C. Maisonneuve, and A. Sebbane. 2010. Recent landscape change at the ecoregion scale in Southern Québec (Canada), 1993-2001. Environmental Monitoring and Assessment 164:631-647.

Jobin, B., C. Latendresse, A. Baril, C. Maisonneuve, C. Boutin, and D. Côté. 2014. A half-century analysis of landscape dynamics in southern Québec, Canada. Environmental Monitoring and Assessment 186:2215-2229.

Kappes, J. J. J. 1997. Defining cavity-associated interactions between Red-Cockaded Woodpeckers and other cavity-dependent species: interspecific competition or cavity kleptoparasitism? Auk 114:778-780.

Kerr, J. T., and J. Cihlar. 2003. Land use and cover with intensity of agriculture for Canada from satellite and census data. Global Ecology and Biogeography 12:161-172.

Kéry, M. 2011. Toward the modelling of true species distributions. Journal of Biogeography 38:617-618.

Kharouba, H. M., A. C. Algar, and J. T. Kerr. 2009. Historically calibrated predictions of butterfly species' range shift using global change as a pseudo-experiment. Ecology 90:2213-2222.

Kimball, S., J. L. Funk, M. J. Spasojevic, K. N. Suding, S. Parker, and M. L. Goulden. 2016. Can functional traits predict plant community response to global change? Ecosphere 7:e01602.

Krebs, J. R., J. D. Wilson, R. B. Bradbury, and G. M. Siriwardena. 1999. The second Silent Spring? Nature 400:611-612.

LaDeau, S. L., A. M. Kilpatrick, and P. P. Marra. 2007. West Nile virus emergence and large-scale declines of North American bird populations. Nature 447:710-713.

Lahoz-Monfort, J. J., G. Guillera-Arroita, and B. A. Wintle. 2014. Imperfect detection impacts the performance of species distribution models. Global Ecology and Biogeography 23:504-515.

Laliberté, E., et al. 2010. Land-use intensification reduces functional redundancy and response diversity in plant communities. Ecology Letters 13:76-86.

Lemelin, L. V., M. Darveau, L. Imbeau, and D. Bordage. 2010. Wetland use and selection by breeding waterbirds in the boreal forest of Quebec, Canada. Wetlands 30:321-332.

Lipsitz, S. R., G. M. Fitzmaurice, E. J. Orav, and N. M. Laird. 1994. Performance of generalized estimating equations in practical situations. Biometrics 50:270-278.

MacLean, S., and S. R. Beissinger. 2017. Species' traits as predictors of range shifts under contemporary climate change: a review and meta-analysis. Global Change Biology 23:4094-4105.

Mantyka-Pringle, C. S., T. G. Martin, and J. R. Rhodes. 2012. Interactions between climate and habitat loss effects on biodiversity: a systematic review and meta-analysis. Global Change Biology 18:1239-1252.

Marmion, M., M. Parviainen, M. Luoto, R. K. Heikkinen, and W. Thuiller. 2009. Evaluation of consensus methods in predictive species distribution modelling. Diversity and Distributions 15:59-69.

Martin, K., K. E. H. Aitken, and K. L. Wiebe. 2004. Nest sites and nest webs for cavity-nesting communities in interior British Columbia, Canada: nest characteristics and niche partitioning. Condor 106:5.

Maruca, S. L., and G. M. Jacquez. 2002. Area-based tests for association between spatial patterns. Journal of Geographical Systems 4:69-83.

Maxwell, S. L., R. A. Fuller, T. M. Brooks, and J. E. M. Watson. 2016. Biodiversity: the ravages of guns, nets and bulldozers. Nature 536:143-145.
McGarigal, K., and W. C. McComb. 1995. Relationships between landscape structure and breeding birds in the Oregon Coast Range. Ecological Monographs 65:235-260.

McPherson, J. M., and W. Jetz. 2007. Effects of species' ecology on the accuracy of distribution models. Ecography 30:135-151.

Millennium Ecosystem Assessment. 2005. Ecosystems and human well-being: synthesis. Island Press, Washington, D.C., USA.

Morán-Ordóñez, A., J. J. Lahoz-Monfort, J. Elith, and B. A. Wintle. 2016. Evaluating 318 continental-scale species distribution models over a 60 year prediction horizon: what factors influence the reliability of predictions? Global Ecology and Biogeography 26:371-384.

Moulds, S. 2017. lulcc: Land Use Change Modelling in R. R package version 1.0.2. https://cran.r-project.org/package=lulcc. https:// cran.r-project.org/package $=$ lulcc

Muntaner, J., X. F. Parareda, and A. Martínez-Vilalta. 1983. Atlas dels ocells nidificants de Catalunya i Andorra [Altas of Breeding Birds of Catalonia and Andorra, in Catalan]. Ketres, Barcelona, Spain.

Nappi, A., and P. Drapeau. 2009. Reproductive success of the black-backed woodpecker (Picoides arcticus) in burned boreal forests: are burns source habitats? Biological Conservation 142:1381-1391.

Nappi, A., P. Drapeau, M. Saint-Germain, and V. A. Angers. 2010. Effect of fire severity on long-term occupancy of burned boreal conifer forests by saproxylic insects and wood-foraging birds. International Journal of Wildland Fire 19:500-511.

Navarro, L. M., and H. M. Pereira. 2012. Rewilding abandoned landscapes in Europe. Ecosystems 15:900-912.

Newbold, T., J. P. W. Scharlemann, S. H. M. Butchart, C. H. Sekercioglu, R. Alkemade, H. Booth, and D. W. Purves. 2012. Ecological traits affect the response of tropical forest bird species to land-use intensity. Proceedings of the Royal Society B 280: 20122131.

Newbold, T., J. P. W. Scharlemann, S. H. M. Butchart, Ç. H. Şekercioğlu, L. Joppa, R. Alkemade, and D. W. Purves. 2014. Functional traits, land-use change and the structure of present and future bird communities in tropical forests. Global Ecology and Biogeography 23:1073-1084.

Newbold, T., et al. 2015. Global effects of land use on local terrestrial biodiversity. Nature 520:45-50.

Ouellet-Lapointe, U., P. Drapeau, P. Cadieux, and L. Imbeau. 2012. Woodpecker excavations suitability for and occupancy by cavity users in the boreal mixedwood forest of eastern Canada. Écoscience 19:391-397.

Pelletier, G., Y. Dumont, and M. Bedard. 2007. SIFORT: Système d'information forestière par tesselle. Manuel de l'usager. (Q. (MRNFQ) Ministère des Ressources naturelles et de la faune, Gouvernement du Québec, Québec, Quebec, Canada.

Pöyry, J., M. Luoto, R. K. Heikkinen, and K. Saarinen. 2008. Species traits are associated with the quality of bioclimatic models. Global Ecology and Biogeography 17:403-414.

Queiroz, C., R. Beilin, C. Folke, and R. Lindborg. 2014. Farmland abandonment: threat or opportunity for biodiversity conservation? A global review. Frontiers in Ecology and the Environment 12:288-296.

$\mathrm{R}$ Core Team. 2015. A language and environment for statistical computing. R Foundation for Statistical Computing, Vienna, Austria.

Randin, C. F., T. Dirnböck, S. Dullinger, N. E. Zimmermann, M. Zappa, and A. Guisan. 2006. Are niche-based species distribution models transferable in space? Journal of Biogeography 33:16891703.

Regos, A., M. Ninyerola, G. Moré, and X. Pons. 2015. Linking land-cover dynamics with driving forces in mountain landscape of the Northwestern Iberian Peninsula. International Journal of Applied Earth Observation and Geoinformation 38:1-14.

Regos, A., J. Domínguez, A. Gil-Tena, L. Brotons, M. Ninyerola, and X. Pons. 2016. Rural abandoned landscapes and bird assemblages: winners and losers in the rewilding of a marginal 
mountain area (NW Spain). Regional Environmental Change 16:199-211.

Regos, A., M. Clavero, M. D'Amen, A. Guisan, and L. Brotons 2018. Wildfire-vegetation dynamics affect predictions of climate change impact on bird communities. Ecography 41:982-995.

Reif, J. 2013. Long-term trends in bird populations: a review of patterns and potential drivers in North America and Europe. Acta Ornithologica 48:1-16.

Rapacciuolo, G., D. B. Roy, S. Gillings, and A. Purvis. 2014. Temporal validation plots: quantifying how well correlative species distribution models predict species' range changes over time. Methods in Ecology and Evolution 5:407-420.

Rodewald, P., editor. 2015. The birds of North America. Cornell Laboratory of Ornithology, Ithaca, New York, USA. https://bird sna.org

Sauer, J. R., W. A. Link, J. E. Fallon, K. L. Pardieck, and D. J. Ziolkowski. 2013. The North American Breeding Bird Survey 1966-2011: summary analysis and species accounts. North American Fauna 79:1-32.

Schmiegelow, F. K. A., and M. Mönkkönen. 2002. Habitat loss and fragmentation in dynamic landscape: avian perspectives from the boreal forest. Ecological Applications 12:375-389.

Secretariat of the Convention on Biological Diversity. 2014. Global biodiversity outlook 4. A midterm assessment of progress toward the implementation of the Strategic Plan for Biodiversity 20112020. Secretariat of the Convention on Biological Diversity, Montréal, Quebec, Canada.

Sharrock, J. T. R. 1976. The Atlas of breeding birds in Britain and Ireland. British Trust for Ornithology and Irish Wildland Conservancy, Pyser, UK.

Sirami, C., L. Brotons, and J.-L. Martin. 2007. Vegetation and songbird response to land abandonment: from landscape to census plot. Diversity \& Distributions 13:42-45.

Sirami, C., L. Brotons, and J.-L. Martin. 2009. Do bird spatial distribution patterns reflect population trends in changing landscapes? Landscape Ecology 24:893-906.

Sirami, C., P. Caplat, S. Popy, A. Clamens, R. Arlettaz, F. Jiguet, L. Brotons, and J.-L. Martin. 2017. Impacts of global change on species distributions: obstacles and solutions to integrate climate and land use. Global Ecology and Biogeography 26:385-394.

Strauss, B., and R. Biedermann. 2007. Evaluating temporal and spatial generality: how valid are species-habitat relationship models? Ecological Modelling 204:104-114.

Syphard, A. D., and J. Franklin. 2010. Species traits affect the performance of species distribution models for plants in southern California. Journal of Vegetation Science 21:177-189.

Tapia, L., A. Regos, A. Gil-Carrera, and J. Domínguez. 2017. Unravelling the response of diurnal raptors to land-use change in a highly dynamic landscape in northwestern Spain: an approach based on satellite earth observation data. European Journal of Wildlife Research 63:40

Thuiller, W., J. Vayreda, J. Pino, S. Sabate, S. Lavorel, and C. Gracia. 2003. Large-scale environmental correlates of forest tree distributions in Catalonia (NE Spain). Global Ecology and Biogeography 12:313-325.
Thuiller, W., B. Lafourcade, R. Engler, and M. B. Araújo. 2009. BIOMOD - a platform for ensemble forecasting of species distributions. Ecography 32:369-373.

Thuiller, W., S. Pironon, A. Psomas, M. Barbet-Massin, F. Jiguet, S. Lavergne, P. B. Pearman, J. Renaud, L. Zupan, and N. E. Zimmermann. 2014. The European functional tree of bird life in the face of global change. Nature Communications 5:3118.

Thuiller, W., R. Engler, and F. T. Breiner. 2016. biomod2: Ensemble Platform for Species Distribution Modeling. R package version 3.3-7. https://CRAN.R-project.org/package=biomod2

Titeux, N., K. Henle, J.-B. Mihoub, and L. Brotons. 2016a. Climate change distracts us from equally important threats to biodiversity. Frontiers in Ecology and the Environment 14:291.

Titeux, N., K. Henle, J.-B. Mihoub, A. Regos, I. R. Geijzendorffer, W. Cramer, P. H. Verburg, and L. Brotons. 2016b. Biodiversity scenarios neglect future land-use change. Global Change Biology 22:2505-2515.

Titeux, N., K. Henle, J.-B. Mihoub, A. Regos, I. R. Geijzendorffer, W. Cramer, P. H. Verburg, and L. Brotons. 2017. Global scenarios for biodiversity need to better integrate climate and land-use change. Diversity and Distributions 23:1231-1234.

Torres, L. G., P. J. H. Sutton, D. R. Thompson, K. Delord, H. Weimerskirch, P. M. Sagar, E. Sommer, B. J. Dilley, P. G. Ryan, and R. A. Phillips. 2015. Poor transferability of species distribution models for a pelagic predator, the grey petrel, indicates contrasting habitat preferences across ocean basins. PLoS ONE 10: e0120014.

Vallecillo, S., L. Brotons, and W. Thuiller. 2009. Dangers of predicting bird species distributions in response to land-cover changes. Ecological Applications 19:538-549.

Vandewalle, M., et al. 2010. Functional traits as indicators of biodiversity response to land-use changes across ecosystems and organisms. Biodiversity and Conservation 19:2921-2947.

Venier, L. A., and S. B. Holmes. 2010. A review of the interaction between forest birds and eastern spruce budworm. Environmental Reviews 18:191-207.

Welsh, A. H., D. B. Lindenmayer, and C. F. Donnelly. 2013. Fitting and interpreting occupancy models. PLoS ONE 8:e52015.

Wenger, S. J., and J. D. Olden. 2012. Assessing transferability of ecological models: an underappreciated aspect of statistical validation. Methods in Ecology and Evolution 3:260-267.

Whelan, C. J., Ç. H. Şekercioğlu, and D. G. Wenny. 2015. Why birds matter: from economic ornithology to ecosystem services. Journal of Ornithology 156:227-238.

Wisz, M. S., R. J. Hijmans, A. T. Peterson, C. H. Graham, and A. Guisan. 2008. Effects of sample size on the performance of species distribution models. Diversity and Distribution 14:763-773.

Wogan, G. O. U. 2016. Life-history traits and niche instability impact accuracy and temporal transferability for historically calibrated distribution models of North American birds. PLoS ONE 11:e0151024.

WWF ZSL. 2016. Living Planet Report 2016. Risk and resilience in a new era. WWF International, Gland, Switzerland.

Yeatman, L. 1976. Atlas des oiseaux nicheurs de France. Société ornithologique de France, Paris, France.

\section{SUPPORTING INFORMATION}

Additional supporting information may be found online at: http://onlinelibrary.wiley.com/doi/10.1002/eap.1784/full

\section{Data Availability}

Bird data at square and point-count level are available via Nature Counts from Bird Studies Canada: https://www.birdscanada.org/bird $\mathrm{mon} /$ default/datasets.jsp?project $=$ qcatlas 